\title{
Functional proteomic analysis of seminal plasma proteins in men with various semen parameters
}

\author{
Rakesh Sharma', Ashok Agarwal ${ }^{1 *}$, Gayatri Mohanty ${ }^{1,6}$, Rachel Jesudasan², Banu Gopalan³, Belinda Willard ${ }^{4}$, \\ Satya P Yadav ${ }^{5}$ and Edmund Sabanegh ${ }^{1}$
}

\begin{abstract}
Background: Alterations at the molecular level in spermatozoa and seminal plasma can affect male fertility. The objective of this study was to determine if analysis of differential expression of proteins in varying semen parameters can serve as potential biomarkers for male infertility.

Methods: The differential expression of proteins in the seminal plasma of men based on sperm count and morphology were examined utilizing proteomic tools. Subjects were categorized based on sperm concentration and morphology into 4 groups: 1) normal sperm count and normal morphology (NN); 2) normal sperm count and abnormal morphology (NA); 3) oligozoospermia and normal morphology (ON); and 4) oligozoospermia and abnormal morphology (OA). Proteomic analysis was performed by LC-MS/MS followed by functional bioinformatics analysis. Protein distribution in the NA, ON and OA groups was compared with that of the NN group.

Results: Twenty proteins were differentially expressed among the 4 groups. Among the unique proteins identified, 3 were downregulated in the NA group, 1 in the ON group and 1 in the OA group while 2 were upregulated in the $\mathrm{ON}$ and $\mathrm{OA}$ groups. The functional analysis 1) identified biological regulation as the major processes affected and 2) determined that most of the identified proteins were of extracellular origin.
\end{abstract}

Conclusions: We have identified proteins that are over-or underexpressed in the seminal plasma of men with poor sperm quality. The distinct presence of some of the proteins may serve as potential biomarkers and provide insight into the mechanistic role played by these proteins in male infertility. Further studies using Western Blot analysis are required to validate these findings.

\section{Background}

Infertility is a major problem in $15 \%$ of couples worldwide. Male factors may play a role in half of these cases [1]. Most causes of male infertility are idiopathic. Semen analysis remains the cornerstone in the evaluation of male infertility. However, the data generated from this routine testing do not provide any insight into the underlying problems associated with developing spermatozoa. Sperm morphology plays an important role in conception, and both fertilization and pregnancy rates are affected when morphologically normal sperms are below $5 \%$. It is also a reflection of poor testicular physiology and is an important factor in male infertility [2-4]. However, a significant overlap of semen parameters such as sperm count, motility and

\footnotetext{
* Correspondence: Agarwaa@ccf.org

'Center for Reproductive Medicine, Glickman Urological and Kidney Institute, Cleveland Clinic, Cleveland, OH, USA

Full list of author information is available at the end of the article
}

morphology have been documented [5]. Idiopathic and unexplained infertility cannot be diagnosed by routine sperm function tests [6]. Similarly, oligozoospermic men may have other underlying pathologies that may contribute to infertility. Evaluation solely based on semen analysis is insufficient to determine the fertility status of the male partner.

Spermatogenesis is a complex process that involves development of the undifferentiated germ cells into a highly specialized spermatozoon capable of fertilizing an oocyte [7]. Fertilization requires physical proximity of the spermatozoa and the oocytes. Seminal plasma composed of secretions from the testis, epididymis and male accessory glands [8] provides a favorable environment and serves as a vehicle for the spermatozoa as it travels to meet the oocyte.

Seminal plasma contains unique proteins necessary for sperm function and survival $[9,10]$. Seminal plasma proteins play a variety of roles-they help protect the sperm

\section{Biomed Central}


by binding to the sperm surface during ejaculation and play a key role in capacitation, acrosome reaction, and sperm-egg fusion $[11,12]$. They can also modulate immune response in male and female reproductive tracts, ensuring that the most competent spermatozoa meet the oocyte during fertilization [13]. Thus, seminal plasma proteins can serve as important biomarkers for male infertility [14].

Conventional 1-Dimensional gel electrophoresis studies have provided information in relation to sperm proteins and their function in normal and abnormal spermatozoa $[15,16]$. Advancements in mass- spectrometry and proteomic-based techniques have made it possible to analyze the complex protein mixtures found in tissues and body fluids. Several attempts have been made to identify these proteins using high-throughput techniques such as matrix assisted laser desorption ionization time of flight (MALDI-TOF) mass spectrometry (MS) and liquid chromatography - tandem mass spectrometry (LC-MS/MS) and linear ion trap (LTQ-Orbitrap) mass spectrometry [17-21].

Alterations at the molecular level in spermatozoa and the seminal plasma may contribute to male infertility. However, even after accounting for all the advances in proteomics, there has been a great lack of detailed data in the area of comparative analysis of seminal plasma proteins associated with male infertility.

The objective of the present study was 1 ) to compare the differential expression of proteins in the seminal plasma from subjects with normal or abnormal sperm concentration and sperm morphology utilizing proteomic tools such as LC-MS/MS and 2) utilize the functional bioinformatics analysis to identify the cellular origin and the differentially affected processes and/or pathways of these proteins to gain insights into the mechanistic roles played by these proteins in effecting the observed phenotypes. These analyses could possibly identify potential biomarkers for male infertility.

\section{Methods}

After obtaining Institutional Review Board approval, written consent was obtained from all subjects. Semen samples were obtained from 64 subjects who were healthy male volunteers of unproven fertility $(n=21)$ and men presenting to our infertility clinic for evaluation $(n=43)$. Semen samples were collected by masturbation after 2-3 days of sexual abstinence. Samples with leukocytospermia--a high concentration of white blood cells $\left(>1 \times 10^{6} \mathrm{WBC} / \mathrm{mL}\right)$-were examined for the presence of granulocytes by the peroxidase or the Endtz test. The patients with a positive Endtz test were excluded from the study. Semen analysis was conducted according to WHO criteria as described below [22].

\section{Semen analysis}

Following complete liquefaction (average time: 20 minutes and no more than $60 \mathrm{~min}$.), manual semen analysis was performed using a MicroCell counting chamber (Vitrolife, San Diego, CA) to determine sperm concentration and percentage motility according to WHO guidelines [22]. Viability was determined with Eosin - Nigrosin stain. Smears of the raw semen were stained with a Diff-Quik kit (Baxter Healthcare Corporation, Inc., McGaw Park, IL) for assessment of sperm morphology according to WHO criteria [22].

After analysis of semen parameters, aliquots of the samples were frozen at $-80^{\circ} \mathrm{C}$ for proteomic analysis.

\section{Preparation of samples for proteomic analysis}

Samples were divided into 4 groups based only on normal sperm concentration and normal morphology parameters according to WHO criteria [22]. The groups were as follows: Group 1: normal sperm count and normal morphology $(\mathrm{NN}=26)$; Group 2: normal sperm count and abnormal morphology $(\mathrm{NA}=22)$; Group 3: oligozoospermia and normal morphology $(\mathrm{ON}=6)$ and group 4: oligozoospermia and abnormal morphology $(\mathrm{OA}=10)$.

To prepare the samples for proteomic analysis, they were thawed, and clear seminal plasma was separated from the sperm pellet by centrifugation at 3,000 g for 30 minutes to ensure complete removal of the cellular components. Seminal plasma samples were pooled into replicates $(\mathrm{NN}=5 ; \mathrm{NA}=4 ; \mathrm{ON}=1 ; \mathrm{OA}=2)$. Each sample was dissolved in $98 \%$ acetonitrile containing $0.1 \%$ trifluoroacetic acid followed by lyophilization at $-80^{\circ} \mathrm{C}$ under vacuum for 2 days. The lyophilized sample was used to estimate the protein content. The samples were first precipitated in cold acetone and centrifuged at $10,000 \mathrm{~g}$ for 15 minutes. The acetone was poured off, and the protein pellet was allowed to dry at room temperature. The protein pellet was solubilized in a buffer of $6 \mathrm{M}$ urea, $100 \mathrm{mM}$ Tris, $\mathrm{pH}$ 8.0. The proteins were then reduced by the addition of DTT $(200 \mathrm{mM}$ in $100 \mathrm{mM}$ Tris) for 15 minutes at room temperature and then alkylated by the addition of $200 \mathrm{mM}$ iodoacetamide (200 $\mathrm{mM}$ in $100 \mathrm{mM}$ Tris) for 20 minutes at room temperature. The urea concentration was then reduced to approximately $1.2 \mathrm{M}$, and trypsin was added at a ratio of 1:50. Digestion was carried out overnight at room temperature. The digestion was stopped the next morning by adding acetic acid to lower the $\mathrm{pH}$ to $<6$, and the samples were centrifuged to remove insoluble material. The digests were then prepared for LC-MS/MS analysis by using PepClean C-18 spin columns to desalt the samples, which were then brought up in $50 \mu \mathrm{L}$ of $1 \%$ acetic acid. 


\section{Liquid chromatography - mass spectrometer analysis (LC-MS/MS)}

The LC-MS system is a Finnigan LTQ linear ion trap mass spectrometer system. The high performance liquid chromatography (HPLC) column was a self-packed $9 \mathrm{~cm} \times 75 \mu \mathrm{m}$ (internal diameter) Phenomenex Jupiter C18 reversed-phase capillary chromatography column. Ten $\mu \mathrm{L}$ volumes of the extract were injected, and the peptides that were eluted from the column by an acetonitrile/ $0.1 \%$ formic acid gradient at a flow rate of $0.25 \mu \mathrm{L} / \mathrm{min}$ were introduced into the source of the mass spectrometer on-line. The microelectrospray ion source was set at $2.5 \mathrm{kV}$. The digest was analyzed using the data-dependent multitask capability of the instrument acquiring full scan mass spectra to determine peptide molecular weights and product ion spectra to determine the amino acid sequence in successive instrument scans [23]. This mode of analysis produces approximately 2500 collision-induced dissociation (CID) spectra of ions ranging in abundance over several orders of magnitude. The spectral count (SC) for each protein was determined. Normalized spectral count (NSC) was obtained by dividing the spectral count for each protein and the total number of spectral counts identified in the sample. The spectral counts were quantitated by taking the normalized spectral count ratio for two sets of samples. A protein was considered to be differentially expressed if there was at least a two-fold difference in the spectral count ratios between the two samples.

\section{Data analysis}

All CID spectra collected in the experiment were used to search the National Center for Biotechnology Information (NCBI) human reference sequence database with the search engine MASCOT (Matrix Science, Boston, MA, www.matrixscience.com). After identification, a database consisting of all proteins identified in these searches was created and used for a second set of searches. These searches were performed with a program called SEQUEST, and the results from these SEQUEST searches were used to determine the spectral counts. Furthermore, functional bioinformatics analysis was done using publicly available software packages such as Gene Ontology annotations from GO Term Finder [24] and GO Term Mapper [25], UniProt [26], STRAP [27], and BioGPS [28]) as well as proprietary software packages (Ingenuity Pathway Analysis (IPA) from Ingenuity Systems [29], and Metacore ${ }^{\mathrm{TM}}$ from GeneGo Inc. [30]) to identify the differentially affected processes, pathways, interactions, and cellular distribution of the proteins in the four study groups.

\section{Results}

Analysis of the proteins identified by LC-MS/MS

The proteins identified in the 12 replicates from NN, $\mathrm{NA}, \mathrm{ON}$ and $\mathrm{OA}$ group showing protein name, NCBI database index, molecular weight, peptide coverage and Mascot score is shown in Table 1. A protein was considered significant if the SC cut off value was $\geq 10$ in at least one sample and present in at least $50 \%$ of the samples in a group. They were considered 'low abundant' if the SC cut-off value was $\leq 10$ in all the samples. The differentially expressed proteins (DEP) in the NA, $\mathrm{OA}$, and $\mathrm{ON}$ groups were categorized based on the NSC ratio cut-off values of $>2$ (for over-expressed) or $<0.5$ (for under-expressed) in comparison to the $\mathrm{NN}$ group. We identified a total of 35 proteins; of these, 10 were classified as low abundant. Amongst the remaining 25 significantly abundant proteins (24 in NN, 23 in NA, 20 in $\mathrm{OA}$, and 16 in $\mathrm{ON}), 11$ were present in all the samples, and 13 proteins were identified as unique to one or two or three of the four samples. 20 proteins were identified as differentially expressed in the NA, OA, and ON groups as compared to $\mathrm{NN}$ group, with 2 proteins differentially expressed in all three groups (Figure 1). The remaining 18 were present in either of the groups (Figure 2). A detailed list of the proteins classified under these categories (Common, Unique, Significant, Low Abundant, and Differentially Expressed) is shown in Table 2.

\section{Identification of the common proteins}

Our analyses revealed a set of 11 proteins that were common to all the samples in the 4 groups (Table 2). Prolactin induced protein (PIP), semenogelin II (SgII) precursor, albumin preprotein, lactotransferrin, epididymal secretory protein E1 precursor, extracellular matrix protein 1 isoform 1 precursor, prosaposin isoform A preprotein, cathepsin D preprotein, prostate specific antigen isoform 1 preprotein, zinc alpha- 2 glycoprotein 1 , and clusterin isoform 1 were the common proteins identified.

\section{Identification of differentially expressed proteins}

As shown in Figure 1, the DEP list encompassed proteins that overlapped with other categories (common, unique, low abundant and significant). The common proteins that were also differentially expressed included prostate specific antigen isoform I preprotein; zinc alpha-2-glycoprotein 1 and clusterin isoform 1 . Five low abundant proteins (transferrin; secretory leukocyte peptidase inhibitor precursor; ubiquitin and ribosomal protein S27a precursor; protein tyrosine phosphatase receptor type, sigma isoform 1 precursor, and acidic epididymal glycoprotein-like 1 isoform 1 precursor) were included as differentially expressed because their NSC ratio comparison met the 2 -fold cutoff criteria. Of the 20 differentially expressed proteins, mucin 6, gastric; orosomucoid 1 precursor and acidic epididymal glycoprotein-like isoform 1 precursor were unique proteins that were down regulated in the NA group. 
Table 1 Identification of proteins in the 12 replicates from NN, NA, ON and OA group showing protein name, NCBI database index, molecular weight, peptide coverage and Mascot score

\begin{tabular}{|c|c|c|c|c|c|}
\hline \multicolumn{4}{|c|}{ Identification } & \multicolumn{2}{|c|}{ LTQ } \\
\hline No. Protein name & $\begin{array}{c}\text { NCBI database index } \\
\text { number }\end{array}$ & $\begin{array}{c}\text { Calculated MW in } \\
\text { kDa }\end{array}$ & PI & $\begin{array}{c}\begin{array}{c}\text { Peptides } \\
\text { (\%coverage) }\end{array} \\
\end{array}$ & $\begin{array}{l}\text { Mascot } \\
\text { score }\end{array}$ \\
\hline \multicolumn{6}{|l|}{ Sample NN1 } \\
\hline semenogelin II precursor & 4506885 & 65 & 9 & $8(10 \%)$ & 9536 \\
\hline prolactin induced protein & 4505821 & 16 & 8.2 & $3(20 \%)$ & 5335 \\
\hline albumin preproprotein & 4502027 & 71 & 5.9 & $9(22 \%)$ & 4805 \\
\hline epididymal secretory protein E1 precursor & 5453678 & 16 & 7.5 & $3(21 \%)$ & 794 \\
\hline prosaposin isoform a preproprotein & 11386147 & 59 & 5 & $1(2 \%)$ & 658 \\
\hline mucin 6, gastric & 151301154 & 263 & 7.2 & $4(3 \%)$ & 461 \\
\hline prostate specific antigen isoform 4 preproprotein & 71834855 & 24 & 7 & $3(15 \%)$ & 460 \\
\hline armadillo repeat protein & 4502247 & 105 & 6.3 & $3(5 \%)$ & 413 \\
\hline cathepsin D preproprotein & 4503143 & 45 & 6.1 & $1(4 \%)$ & 285 \\
\hline zinc alpha-2-glycoprotein 1 & 4502337 & 34 & 5.7 & $2(12 \%)$ & 260 \\
\hline cystatin S precursor & 4503109 & 16 & 4.9 & $2(31 \%)$ & 178 \\
\hline ubiquitin and ribosomal protein S27a precursor & 4506713 & 18 & 9.6 & $1(10 \%)$ & 173 \\
\hline clusterin isoform 1 & 42716297 & 58 & 6.2 & $3(10 \%)$ & 142 \\
\hline \multicolumn{6}{|l|}{ Sample NN2 } \\
\hline prolactin-induced protein & 4505821 & 16 & 8.2 & $10(69 \%)$ & 32886 \\
\hline semenogelin II precursor & 4506885 & 65 & 9 & $17(33 \%)$ & 22468 \\
\hline semenogelin I isoform b preproprotein & 38049014 & 45 & 9.2 & $13(33 \%)$ & 5388 \\
\hline albumin preproprotein & 4502027 & 71 & 5.9 & $24(54 \%)$ & 15508 \\
\hline prostate specific antigen isoform 1 preproprotein & 4502173 & 29 & 7.6 & $11(61 \%)$ & 5087 \\
\hline lactotransferrin precursor & 54607120 & 80 & 8.5 & $22(42 \%)$ & 4281 \\
\hline zinc alpha-2-glycoprotein 1 & 4502337 & 34 & 5.7 & $11(44 \%)$ & 3424 \\
\hline cystatin S precursor & 4503109 & 16 & 4.9 & $5(44 \%)$ & 1809 \\
\hline prosaposin isoform a preproprotein & 11386147 & 59 & 5 & $9(33 \%)$ & 880 \\
\hline epididymal secretory protein E1 precursor & 5453678 & 16 & 7.5 & $4(52 \%)$ & 786 \\
\hline serine proteinase inhibitor, clade A, member 1 & 50363217 & 46 & 5.3 & $11(48 \%)$ & 737 \\
\hline mucin 6, gastric & 151301154 & 263 & 7.2 & $11(9 \%)$ & 524 \\
\hline extracellular matrix protein 1 isoform 1 precursor & 221316614 & 62 & 6.2 & $7(31 \%)$ & 504 \\
\hline cystatin C precursor & 4503107 & 16 & 9 & $6(68 \%)$ & 432 \\
\hline tissue inhibitor of metalloproteinase 1 precursor & 4507509 & 23 & 8.4 & $4(40 \%)$ & 411 \\
\hline fibronectin 1 isoform 3 preproprotein & 16933542 & 262 & 5.4 & $8(11 \%)$ & 353 \\
\hline cathepsin D preproprotein & 4503143 & 45 & 6.1 & $3(11 \%)$ & 266 \\
\hline acid phosphatase, prostate short isoform precursor & 6382064 & 44 & 5.8 & $2(12 \%)$ & 166 \\
\hline carboxypeptidase E preproprotein & 4503009 & 53 & 5 & $5(20 \%)$ & 153 \\
\hline clusterin isoform 1 & 42716297 & 58 & 6.2 & $2(7 \%)$ & 106 \\
\hline \multicolumn{6}{|l|}{ Sample NN3 } \\
\hline prolactin-induced protein & 4505821 & 16 & 8.2 & $10(66 \%)$ & 24697 \\
\hline semenogelin II precursor & 4506885 & 65 & 9 & $19(35 \%)$ & 13533 \\
\hline semenogelin I isoform b preproprotein & 38049014 & 45 & 9.2 & $15(39 \%)$ & 2633 \\
\hline albumin preproprotein & 4502027 & 71 & 5.9 & $30(60 \%)$ & 8842 \\
\hline prostate specific antigen isoform 1 preproprotein & 4502173 & 29 & 7.6 & $16(70 \%)$ & 8634 \\
\hline lactotransferrin precursor & 54607120 & 80 & 8.5 & $23(49 \%)$ & 4607 \\
\hline
\end{tabular}


Table 1 Identification of proteins in the 12 replicates from NN, NA, ON and OA group showing protein name, NCBI database index, molecular weight, peptide coverage and Mascot score (Continued)

\begin{tabular}{|c|c|c|c|c|c|}
\hline zinc alpha-2-glycoprotein 1 & 4502337 & 34 & 5.7 & $9(42 \%)$ & 3935 \\
\hline epididymal secretory protein E1 precursor & 5453678 & 16 & 7.5 & $6(52 \%)$ & 1214 \\
\hline tissue inhibitor of metalloproteinase 1 precursor & 4507509 & 23 & 8.4 & $3(29 \%)$ & 987 \\
\hline prosaposin isoform a preproprotein & 11386147 & 59 & 5 & $5(21 \%)$ & 833 \\
\hline extracellular matrix protein 1 isoform 1 precursor & 221316614 & 62 & 6.2 & $6(22 \%)$ & 766 \\
\hline cystatin S precursor & 4503109 & 16 & 4.9 & $5(49 \%)$ & 621 \\
\hline beta 2 microglobulin precursor & 4757826 & 13 & 6 & $2(21 \%)$ & 523 \\
\hline fibronectin 1 isoform 3 preproprotein & 16933542 & 262 & 5.4 & $4(2 \%)$ & 410 \\
\hline orosomucoid 1 precursor & 167857790 & 23 & 5 & $3(16 \%)$ & 397 \\
\hline cystatin $C$ precursor & 4503107 & 16 & 9 & $3(26 \%)$ & 301 \\
\hline mucin 6, gastric & 151301154 & 263 & 7.2 & $7(7 \%)$ & 288 \\
\hline cathepsin D preproprotein & 4503143 & 45 & 6.1 & $2(11 \%)$ & 228 \\
\hline carboxypeptidase E preproprotein & 4503009 & 53 & 5 & $3(16 \%)$ & 193 \\
\hline acidic epididymal glycoprotein-like 1 isoform 1 precursor & 25121982 & 29 & 5.5 & $2(10 \%)$ & 166 \\
\hline galectin 3 binding protein & 5031863 & 66 & 5.1 & $4(11 \%)$ & 165 \\
\hline clusterin isoform 1 & 42716297 & 58 & 6.2 & $2(7 \%)$ & 158 \\
\hline acid phosphatase, prostate short isoform precursor & 6382064 & 44 & 5.8 & $5(16 \%)$ & 128 \\
\hline prostaglandin (H2) D-isomerase -1 peptide & 32171249 & 21 & 7.6 & $1(8 \%)$ & 115 \\
\hline \multicolumn{6}{|l|}{ Sample NN4 } \\
\hline prolactin-induced protein & 4505821 & 16 & 8.2 & $12(76 \%)$ & 36052 \\
\hline semenogelin II precursor & 4506885 & 65 & 9 & $16(32 \%)$ & 17746 \\
\hline semenogelin I isoform b preproprotein & 38049014 & 45 & 9.2 & $14(34 \%)$ & 2723 \\
\hline lactotransferrin precursor & 54607120 & 80 & 8.5 & $39(61 \%)$ & 8695 \\
\hline albumin preproprotein & 4502027 & 71 & 5.9 & $23(48 \%)$ & 8361 \\
\hline prostate specific antigen isoform 1 preproprotein & 4502173 & 29 & 7.6 & $15(67 \%)$ & 7417 \\
\hline zinc alpha-2-glycoprotein 1 & 4502337 & 34 & 5.7 & $11(38 \%)$ & 3979 \\
\hline mucin 6, gastric & 151301154 & 263 & 7.2 & $14(12 \%)$ & 1685 \\
\hline epididymal secretory protein E1 precursor & 5453678 & 16 & 7.5 & $7(70 \%)$ & 1428 \\
\hline acid phosphatase, prostate short isoform precursor & 6382064 & 44 & 5.8 & $9(26 \%)$ & 1384 \\
\hline clusterin isoform 1 & 42716297 & 58 & 6.2 & $6(16 \%)$ & 1148 \\
\hline orosomucoid 1 precursor & 167857790 & 23 & 5 & $4(32 \%)$ & 942 \\
\hline orosomucoid 2 & 4505529 & 23 & 5 & $2(12 \%)$ & 207 \\
\hline prosaposin isoform a preproprotein & 11386147 & 59 & 5 & $6(27 \%)$ & 941 \\
\hline extracellular matrix protein 1 isoform 1 precursor & 221316614 & 62 & 6.2 & $7(25 \%)$ & 731 \\
\hline tissue inhibitor of metalloproteinase 1 precursor & 4507509 & 23 & 8.4 & $3(29 \%)$ & 635 \\
\hline beta 2 microglobulin precursor & 4757826 & 13 & 6 & $2(21 \%)$ & 489 \\
\hline fibronectin 1 isoform 3 preproprotein & 16933542 & 262 & 5.4 & $4(3 \%)$ & 447 \\
\hline cystatin C precursor & 4503107 & 16 & 9 & $3(26 \%)$ & 391 \\
\hline carboxypeptidase E preproprotein & 4503009 & 53 & 5 & $4(14 \%)$ & 358 \\
\hline galectin 3 binding protein & 5031863 & 66 & 5.1 & $5(14 \%)$ & 341 \\
\hline transferrin & 4557871 & 79 & 6.8 & $2(4 \%)$ & 275 \\
\hline acidic epididymal glycoprotein-like 1 isoform 1 precursor & 25121982 & 29 & 5.5 & $2(10 \%)$ & 238 \\
\hline cystatin S precursor & 4503109 & 16 & 4.9 & $2(20 \%)$ & 205 \\
\hline serine proteinase inhibitor, clade $A$, member 1 & 50363217 & 46 & 5.3 & $3(12 \%)$ & 187 \\
\hline
\end{tabular}


Table 1 Identification of proteins in the 12 replicates from NN, NA, ON and OA group showing protein name, NCBI database index, molecular weight, peptide coverage and Mascot score (Continued)

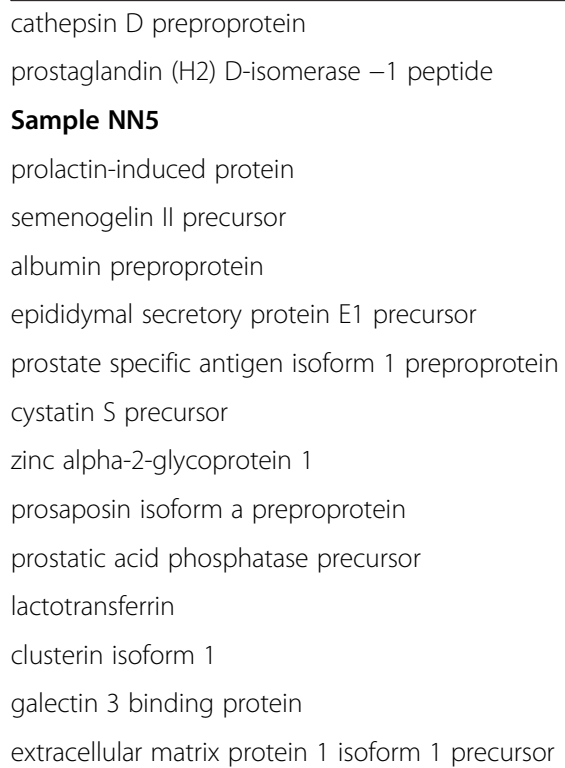

\section{Sample NA1}

prolactin-induced protein

albumin preproprotein

semenogelin II precursor

semenogelin I isoform b preproprotein

prostate specific antigen isoform 1 preproprotein

lactotransferrin

zinc alpha-2-glycoprotein 1

epididymal secretory protein E1 precursor

extracellular matrix protein 1 isoform 1 precursor

serine proteinase inhibitor, clade A, member 1

tissue inhibitor of metalloproteinase 1 precursor

prosaposin isoform a preproprotein

beta 2 microglobulin precursor

fibronectin 1 isoform 3 preproprotein

cystatin C precursor

cystatin S precursor

mucin 6, gastric isoform 1

prostaglandin (H2) D-isomerase

prostatic acid phosphatase precursor

protein tyrosine phosphatase, receptor type, sigma isoform 1

precursor

transferrin

clusterin isoform 1

cathepsin D preproprotein

galectin 3 binding protein

\section{Sample NA2}

prolactin-induced protein

\author{
4503143
}

32171249

4505821

4506885

4502027

5453678

4502173

4503109

4502337

11386147

6382064

54607120

42716297

5031863

4758236

4505821

4502027

4506885

38049014

4502173

54607120

4502337

5453678

221316614

50363217

4507509

11386147

4757826

16933542

4503107

4503109

89033736

32171249

6382064

104487006

4557871

42716297

4503143

5031863

4505821

45

21

$\begin{array}{ccc}6.1 & 2(11 \%) & 185 \\ 7.6 & 1(8 \%) & 133\end{array}$

16

65

65

71

16

29

16

34

59

44

80

58

66

62

16

71

65

45

45

29

80

34

16

$\begin{array}{ccc}8.2 & 8(44 \%) & 15001 \\ 9 & 10(14 \%) & 7235 \\ 5.9 & 17(39 \%) & 2621 \\ 7.5 & 3(23 \%) & 552 \\ 7.6 & 5(22 \%) & 539 \\ 4.9 & 2(23 \%) & 332 \\ 5.7 & 4(19 \%) & 250 \\ 5 & 1(2 \%) & 239 \\ 5.8 & 2(4 \%) & 180 \\ 8.5 & 4(10 \%) & 173 \\ 6.2 & 2(7 \%) & 157 \\ 5.1 & 2(4 \%) & 152 \\ 6.2 & 1(5 \%) & 119\end{array}$

$$
\begin{array}{lll}
8.2 & 10(62 \%) & 17127 \\
5.9 & 36(61 \%) & 9157
\end{array}
$$$$
922(39 \%) \quad 7469
$$$$
9.219(42 \%) \quad 2622
$$$$
7.6 \quad 14(67 \%) \quad 5287
$$$$
8.519(40 \%) \quad 2696
$$$$
5.7 \quad 9(38 \%) \quad 1904
$$$$
7.5 \quad 6(68 \%) \quad 1228
$$$$
6.2 \quad 6(22 \%) \quad 635
$$$$
5.3 \quad 8(27 \%) \quad 616
$$$$
8.42(19 \%) \quad 487
$$$$
54(15 \%) \quad 475
$$$$
6 \quad 2(21 \%) \quad 400
$$$$
5.4 \quad 7(5 \%) \quad 398
$$$$
93(26 \%) \quad 340
$$$$
4.92(20 \%) \quad 261
$$$$
6.3 \quad 4(5 \%) \quad 238
$$$$
\begin{array}{lll}
7.6 & 1(8 \%) & 227
\end{array}
$$$$
5.8 \quad 4(8 \%) \quad 189
$$$$
6.1 \quad 5(5 \%) \quad 180
$$

$6.8 \quad 3(17 \%) \quad 174$

$6.24(11 \%) \quad 171$

$6.1 \quad 1(4 \%) \quad 149$

$5.15(14 \%) \quad 101$

$8.2 \quad 12(76 \%) \quad 21197$


Table 1 Identification of proteins in the 12 replicates from NN, NA, ON and OA group showing protein name, NCBI database index, molecular weight, peptide coverage and Mascot score (Continued)

\begin{tabular}{|c|c|c|c|c|c|}
\hline semenogelin II precursor & 4506885 & 65 & 9 & $18(36 \%)$ & 9137 \\
\hline semenogelin I isoform b preproprotein & 38049014 & 45 & 9.2 & $13(33 \%)$ & 1777 \\
\hline albumin preproprotein & 4502027 & 71 & 5.9 & $26(55 \%)$ & 7695 \\
\hline prostate specific antigen isoform 1 preproprotein & 4502173 & 29 & 7.6 & $16(67 \%)$ & 4963 \\
\hline zinc alpha-2-glycoprotein 1 & 4502337 & 34 & 5.7 & $13(44 \%)$ & 3134 \\
\hline lactotransferrin & 54607120 & 80 & 8.5 & $24(46 \%)$ & 3105 \\
\hline epididymal secretory protein E1 precursor & 5453678 & 16 & 7.5 & $5(68 \%)$ & 1276 \\
\hline prosaposin isoform a preproprotein & 11386147 & 59 & 5 & $7(26 \%)$ & 662 \\
\hline tissue inhibitor of metalloproteinase 1 precursor & 4507509 & 23 & 8.4 & $3(29 \%)$ & 660 \\
\hline serine proteinase inhibitor, clade $A$, member 1 & 50363217 & 46 & 5.3 & $5(20 \%)$ & 612 \\
\hline extracellular matrix protein 1 isoform 1 precursor & 4758236 & 62 & 6.2 & $7(22 \%)$ & 577 \\
\hline cystatin C precursor & 4503107 & 16 & 9 & $3(26 \%)$ & 548 \\
\hline beta 2 microglobulin precursor & 4757826 & 13 & 6 & $2(21 \%)$ & 443 \\
\hline prostatic acid phosphatase precursor & 6382064 & 44 & 5.8 & $8(18 \%)$ & 410 \\
\hline cathepsin D preproprotein & 4503143 & 45 & 6.1 & $5(25 \%)$ & 375 \\
\hline clusterin isoform 1 & 42716297 & 58 & 6.2 & $2(7 \%)$ & 308 \\
\hline DJ-1 protein & 31543380 & 20 & 6.3 & $2(26 \%)$ & 279 \\
\hline carboxypeptidase E preproprotein & 4503009 & 53 & 5 & $4(19 \%)$ & 278 \\
\hline galectin 3 binding protein & 5031863 & 66 & 5.1 & $5(14 \%)$ & 266 \\
\hline cystatin S precursor & 4503109 & 16 & 4.9 & $6(64 \%)$ & 212 \\
\hline CD177 molecule & 110735433 & 47 & 5.6 & $2(9 \%)$ & 199 \\
\hline mucin 6, gastric isoform 1 & 89033736 & 185 & 6.3 & $3(4 \%)$ & 196 \\
\hline fibronectin 1 isoform 3 preproprotein & 16933542 & 262 & 5.4 & $4(4 \%)$ & 172 \\
\hline secretory leukocyte peptidase inhibitor precursor & 4507065 & 15 & 9.1 & $2(28 \%)$ & 162 \\
\hline cathepsin B preproprotein & 4503139 & 38 & 5.8 & $3(12 \%)$ & 127 \\
\hline \multicolumn{6}{|l|}{ Sample NA3 } \\
\hline prolactin-induced protein & 4505821 & 16 & 8.2 & $5(37 \%)$ & 6642 \\
\hline semenogelin II precursor & 4506885 & 65 & 9 & $6(9 \%)$ & 5126 \\
\hline albumin preproprotein & 4502027 & 71 & 5.9 & $7(17 \%)$ & 2077 \\
\hline prosaposin isoform a preproprotein & 11386147 & 59 & 5 & $2(8 \%)$ & 438 \\
\hline mucin 6, gastric isoform 1 & 89033736 & 185 & 6.3 & $3(2 \%)$ & 269 \\
\hline epididymal secretory protein E1 precursor & 5453678 & 16 & 7.5 & $2(21 \%)$ & 210 \\
\hline zinc alpha-2-glycoprotein 1 & 4502337 & 34 & 5.7 & $3(24 \%)$ & 203 \\
\hline prostate specific antigen isoform 1 preproprotein & 4502173 & 29 & 7.6 & $3(13 \%)$ & 141 \\
\hline clusterin isoform 1 & 42716297 & 58 & 6.2 & $3(10 \%)$ & 117 \\
\hline \multicolumn{6}{|l|}{ Sample NA4 } \\
\hline prolactin-induced protein & 4505821 & 16 & 8.2 & 10(76\%) & 22296 \\
\hline semenogelin II precursor & 4506885 & 65 & 9 & $16(30 \%)$ & 11486 \\
\hline semenogelin I isoform b preproprotein & 38049014 & 45 & 9.2 & $13(33 \%)$ & 3038 \\
\hline prostate specific antigen isoform 1 preproprotein & 4502173 & 29 & 7.6 & $14(67 \%)$ & 3631 \\
\hline zinc alpha-2-glycoprotein 1 & 4502337 & 34 & 5.7 & $11(38 \%)$ & 3260 \\
\hline lactotransferrin & 54607120 & 80 & 8.5 & $16(45 \%)$ & 2926 \\
\hline prosaposin isoform a preproprotein & 11386147 & 59 & 5 & $5(20 \%)$ & 773 \\
\hline epididymal secretory protein E1 precursor & 5453678 & 16 & 7.5 & $3(39 \%)$ & 533 \\
\hline
\end{tabular}


Table 1 Identification of proteins in the 12 replicates from NN, NA, ON and OA group showing protein name, NCBI database index, molecular weight, peptide coverage and Mascot score (Continued)

\begin{tabular}{|c|c|c|c|c|c|}
\hline serine proteinase inhibitor, clade $A$, member 1 & 50363217 & 46 & 5.3 & $4(12 \%)$ & 506 \\
\hline extracellular matrix protein 1 isoform 1 precursor & 4758236 & 62 & 6.2 & $4(17 \%)$ & 454 \\
\hline beta 2 microglobulin precursor & 4757826 & 13 & 6 & $2(21 \%)$ & 388 \\
\hline tissue inhibitor of metalloproteinase 1 precursor & 4507509 & 23 & 8.4 & $3(29 \%)$ & 351 \\
\hline cystatin S precursor & 4503109 & 16 & 4.9 & $5(48 \%)$ & 321 \\
\hline cystatin C precursor & 4503107 & 16 & 9 & $2(26 \%)$ & 280 \\
\hline cathepsin D preproprotein & 4503143 & 45 & 6.1 & $2(11 \%)$ & 200 \\
\hline cathepsin B preproprotein & 4503139 & 38 & 5.8 & $2(10 \%)$ & 186 \\
\hline carboxypeptidase E preproprotein & 4503009 & 53 & 5 & $3(11 \%)$ & 162 \\
\hline \multicolumn{6}{|l|}{ Sample OA1 } \\
\hline prolactin-induced protein & 4505821 & 16 & 8.2 & $12(77 \%)$ & 22670 \\
\hline semenogelin II precursor & 4506885 & 65 & 9 & 19(32\%) & 13764 \\
\hline semenogelin I isoform b preproprotein & 38049014 & 45 & 9.2 & $15(27 \%)$ & 6586 \\
\hline albumin preproprotein & 4502027 & 71 & 5.9 & $26(51 \%)$ & 7715 \\
\hline lactotransferrin & 54607120 & 80 & 8.5 & $28(54 \%)$ & 5063 \\
\hline prostate specific antigen isoform 1 preproprotein & 4502173 & 29 & 7.6 & $11(64 \%)$ & 3309 \\
\hline zinc alpha-2-glycoprotein 1 & 4502337 & 34 & 5.7 & $9(40 \%)$ & 3298 \\
\hline ankyrin repeat domain 11 & 56676397 & 299 & 6.7 & $3(1 \%)$ & 1056 \\
\hline PREDICTED: mucin 6, gastric isoform 1 & 89033736 & 185 & 6.3 & $10(14 \%)$ & 808 \\
\hline epididymal secretory protein E1 precursor & 5453678 & 16 & 7.5 & $7(70 \%)$ & 635 \\
\hline clusterin isoform 1 & 42716297 & 58 & 6.2 & $4(13 \%)$ & 512 \\
\hline fibronectin 1 isoform 2 preproprotein & 47132551 & 269 & 5.3 & $10(7 \%)$ & 503 \\
\hline extracellular matrix protein 1 isoform 1 precursor & 4758236 & 62 & 6.2 & $5(28 \%)$ & 420 \\
\hline prosaposin isoform a preproprotein & 11386147 & 59 & 5 & $4(18 \%)$ & 407 \\
\hline prostatic acid phosphatase precursor & 6382064 & 44 & 5.8 & $9(28 \%)$ & 365 \\
\hline tissue inhibitor of metalloproteinase 1 precursor & 4507509 & 23 & 8.4 & $4(35 \%)$ & 337 \\
\hline beta 2 microglobulin precursor - 1 peptide & 4757826 & 13 & 6 & $1(18 \%)$ & 262 \\
\hline serine proteinase inhibitor, clade $A$, member 1 & 50363217 & 46 & 5.3 & $4(12 \%)$ & 242 \\
\hline transferrin & 4557871 & 79 & 6.8 & $3(4 \%)$ & 211 \\
\hline cathepsin D preproprotein & 4503143 & 45 & 6.1 & $2(11 \%)$ & 206 \\
\hline cystatin C precursor & 4503107 & 16 & 9 & $5(52 \%)$ & 199 \\
\hline cystatin S precursor & 4503109 & 16 & 4.9 & $6(68 \%)$ & 198 \\
\hline secretory leukocyte peptidase inhibitor precursor -1 peptide & 4507065 & 15 & 9.1 & $1(18 \%)$ & 175 \\
\hline carboxypeptidase E preproprotein & 4503009 & 53 & 5 & $2(8 \%)$ & 123 \\
\hline galectin 3 binding protein & 5031863 & 66 & 5.1 & $3(8 \%)$ & 105 \\
\hline cathepsin B preproprotein & 4503139 & 38 & 5.8 & $2(12 \%)$ & 95 \\
\hline expressed in prostate and testis & 19923082 & 14 & 8.2 & $1(10 \%)$ & 86 \\
\hline macrophage migration inhibitory factor - 1 peptide & 4505185 & 12 & 7.7 & $1(9 \%)$ & 84 \\
\hline prostaglandin (H2) D-isomerase -1 peptide & 32171249 & 21 & 7.6 & $1(8 \%)$ & 75 \\
\hline \multicolumn{6}{|l|}{ Sample OA2 } \\
\hline prolactin-induced protein & 4505821 & 16 & 8.2 & $8(51 \%)$ & 13511 \\
\hline semenogelin II precursor & 4506885 & 65 & 9 & $11(18 \%)$ & 6235 \\
\hline albumin preproprotein & 4502027 & 71 & 5.9 & $10(23 \%)$ & 1848 \\
\hline cystatin S precursor & 4503109 & 16 & 4.9 & $3(28 \%)$ & 522 \\
\hline
\end{tabular}


Table 1 Identification of proteins in the 12 replicates from NN, NA, ON and OA group showing protein name, NCBI database index, molecular weight, peptide coverage and Mascot score (Continued)

\begin{tabular}{|c|c|c|c|c|c|}
\hline & & & & & \\
\hline prostate specific antigen isoform 4 preproprotein & 71834855 & 24 & 7 & $4(25 \%)$ & 354 \\
\hline prosaposin isoform a preproprotein & 11386147 & 59 & 5 & $1(2 \%)$ & 324 \\
\hline clusterin isoform 1 & 42716297 & 58 & 6.2 & $3(10 \%)$ & 308 \\
\hline mucin 6, gastric isoform 1 & 89033736 & 185 & 6.3 & $2(1 \%)$ & 306 \\
\hline zinc alpha-2-glycoprotein 1 & 4502337 & 34 & 5.7 & $4(17 \%)$ & 291 \\
\hline epididymal secretory protein E1 precursor & 5453678 & 16 & 7.5 & $3(38 \%)$ & 184 \\
\hline ankyrin repeat domain 11 & 56676397 & 299 & 6.7 & $3(1 \%)$ & 133 \\
\hline carboxypeptidase E preproprotein & 4503009 & 53 & 5 & $2(8 \%)$ & 121 \\
\hline lactotransferrin precursor & 54607120 & 80 & 8.5 & $3(9 \%)$ & 115 \\
\hline extracellular matrix protein 1 isoform 1 precursor & 4758236 & 62 & 6.2 & $1(5 \%)$ & 108 \\
\hline galectin 3 binding protein & 5031863 & 66 & 5.1 & $1(2 \%)$ & 98 \\
\hline cathepsin D preproprotein & 4503143 & 45 & 6.1 & $2(13 \%)$ & 95 \\
\hline lactamase, beta isoform a & 26051231 & 61 & 8.7 & $2(10 \%)$ & 90 \\
\hline prostatic acid phosphatase precursor & 6382064 & 44 & 5.8 & $1(4 \%)$ & 78 \\
\hline Sample ON & & & & & \\
\hline prolactin-induced protein & 4505821 & 16 & 8.2 & $9(69 \%)$ & 33212 \\
\hline semenogelin II precursor & 4506885 & 65 & 9 & $20(35 \%)$ & 10703 \\
\hline semenogelin I isoform b preproprotein & 38049014 & 45 & 9.2 & $17((38 \%)$ & 2722 \\
\hline albumin preproprotein & 4502027 & 71 & 5.9 & $25(52 \%)$ & 9519 \\
\hline prostate specific antigen isoform 1 preproprotein & 4502173 & 29 & 7.6 & $14(62 \%)$ & 6487 \\
\hline zinc alpha-2-glycoprotein 1 & 4502337 & 34 & 5.7 & $9(38 \%)$ & 5967 \\
\hline lactotransferrin precursor & 54607120 & 80 & 8.5 & $18(40 \%)$ & 3770 \\
\hline serine proteinase inhibitor, clade A, member 1 & 50363217 & 46 & 5.3 & $4(15 \%)$ & 1138 \\
\hline prosaposin isoform a preproprotein & 11386147 & 59 & 5 & $6(26 \%)$ & 1014 \\
\hline epididymal secretory protein E1 precursor & 5453678 & 16 & 7.5 & $3(39 \%)$ & 937 \\
\hline tissue inhibitor of metalloproteinase 1 precursor & 4507509 & 23 & 8.4 & $2(19 \%)$ & 866 \\
\hline extracellular matrix protein 1 isoform 1 precursor & 221316614 & 62 & 6.2 & $3(12 \%)$ & 637 \\
\hline beta 2 microglobulin precursor & 4757826 & 13 & 6 & $2(21 \%)$ & 633 \\
\hline mucin 6, gastric & 151301154 & 263 & 7.2 & $5(5 \%)$ & 407 \\
\hline fibronectin 1 isoform 3 preproprotein & 16933542 & 262 & 5.4 & $2(1 \%)$ & 352 \\
\hline cathepsin D preproprotein & 4503143 & 45 & 6.1 & $2(11 \%)$ & 334 \\
\hline cystatin C precursor & 4503107 & 16 & 9 & $3(26 \%)$ & 320 \\
\hline carboxypeptidase E preproprotein & 4503009 & 53 & 5 & $3(11 \%)$ & 172 \\
\hline clusterin isoform 1 & 42716297 & 58 & 6.2 & $2(7 \%)$ & 147 \\
\hline acid phosphatase, prostate short isoform precursor & 6382064 & 44 & 5.8 & $3(8 \%)$ & 132 \\
\hline secretory leukocyte peptidase inhibitor precursor & 4507065 & 15 & 9.1 & $2(42 \%)$ & 123 \\
\hline $\begin{array}{l}\text { protein tyrosine phosphatase, receptor type, sigma isoform } 1 \\
\text { precursor }\end{array}$ & 104487006 & 218 & 6.1 & $4(3 \%)$ & 112 \\
\hline
\end{tabular}

The proteins identified as unique and upregulated in the OA group were: prostate specific antigen isoform 1 preprotein; semenogelin I isoform $\mathrm{b}$ preprotein. Cystatin $\mathrm{C}$ precursor was found to be downregulated in the $\mathrm{OA}$ group. The $\mathrm{ON}$ group showed an upregulation of two unique proteins (zinc alpha-2 glycoprotein 1 and tissue inhibitor of metalloproteinase
1 precursor); while clusterin 1 was downregulated in this group.

Some unique proteins were absent in some of the groups but were differentially expressed in other groups. These proteins included the DJ-1 protein, which was absent in the OA groups, whereas the ankyrin repeat domain 11 was absent in the NN group. Also included 


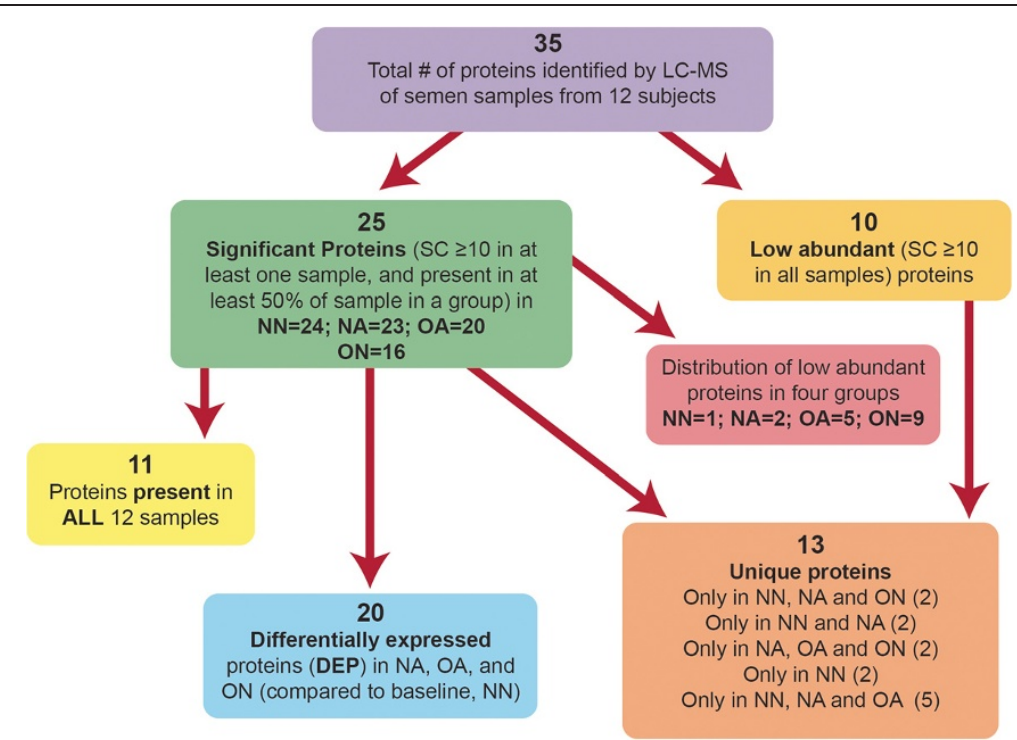

Figure 1 Broad categorical analysis of proteomics data. Differentially expressed proteins list encompasses proteins that overlap with other categories (common, unique, low abundant and significant) of proteins.

in this category was orosomucoid 1 precursor, which was found in significant abundance in the NN samples but in low abundance in NA sample.

\section{Identification of the low abundant proteins}

Many of the identified proteins were low abundant proteins $(\mathrm{SC} \leq 10)$ (Table 2$)$. Some of these proteins were restricted to a particular group while they were absent in other groups. Transferrin, secretory leukocyte peptidase inhibitor precursor, ubiquitin and ribosomal protein S27 a precursor, prostaglandin $\mathrm{H} 2 \mathrm{D}$ isomerase were some of the proteins that were absent in ON group. The CD177 molecule was absent only in the NN group; while orosomucoid 2 was present only in the NN. Protein tyrosine phosphatase, receptor type, sigma isoform 1 precursor and acidic epididymal glycoprotein - like 1 isoform 1 precursor protein were absent in the OA group.

\section{Cellular distribution and significant biological processes for proteins in four groups}

The functional analysis revealed that most of the significant proteins in each of the four groups (NN, NA, OA, and $\mathrm{ON}$ ) had a predominant cellular distribution in the extracellular region followed by their presence in the intracellular organelles (Figure 3). The distribution of

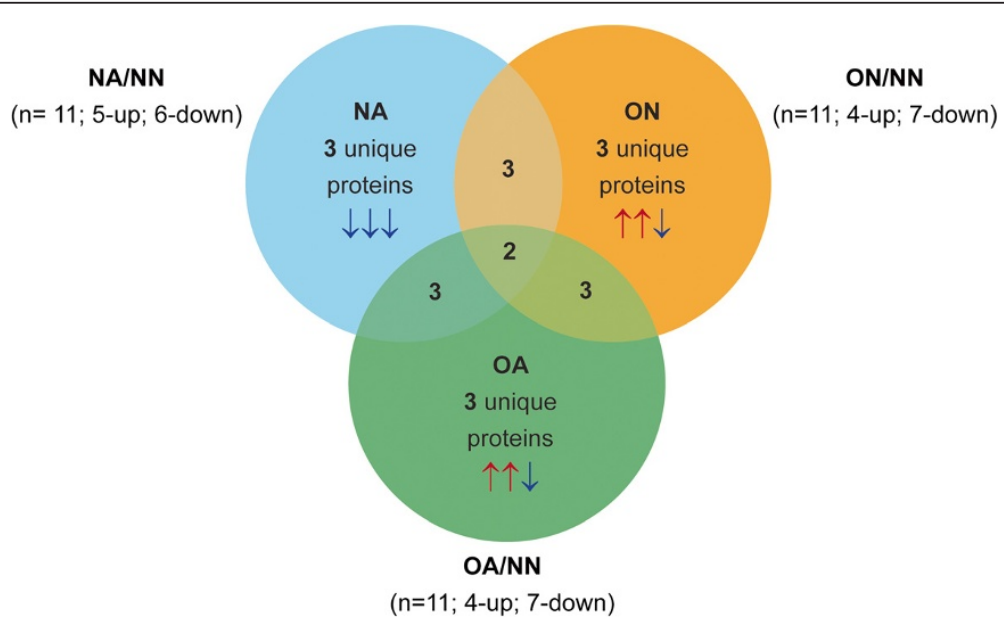

Figure 2 Venn diagram showing distribution of 20 differentially expressed proteins. This was based on the NSC ratio cut-off $>2$ across 3 samples, NA, OA, and ON in comparison to the baseline NN sample. 
Table 2 Detailed list of classification of 35 proteins based on their presence, abundance, and differential expression

\begin{tabular}{|c|c|c|c|c|c|c|c|c|}
\hline No. & Protein Names & $\begin{array}{l}\text { NCBI } \\
\text { Accession } \\
\text { No. }\end{array}$ & $\begin{array}{l}\text { UniProt } \\
\text { Accession } \\
\text { No. }\end{array}$ & $\begin{array}{l}\text { No. of } \\
\text { samples }\end{array}$ & $\begin{array}{l}\text { Proteins } \\
\text { present in } \\
\text { groups }\end{array}$ & $\begin{array}{l}\text { Low } \\
\text { abundant } \\
\text { proteins } \\
(\mathrm{SC} \leq 10)\end{array}$ & $\begin{array}{c}\text { Differentially Expressed } \\
\text { Proteins (in NA, OA, and ON) } \\
\text { compared to NN }\end{array}$ & $\begin{array}{l}\text { Significant } \\
\text { proteins in } \\
\text { groups }\end{array}$ \\
\hline 1 & prolactin-induced protein & 4505821 & P12273 & 12 & $\begin{array}{c}\mathrm{NN}(5), \mathrm{NA} \\
(4), \mathrm{OA}(2), \\
\mathrm{ON}(1)\end{array}$ & & & $\begin{array}{l}\text { NN, NA, OA, } \\
\text { ON }\end{array}$ \\
\hline 2 & semenogelin II precursor & 4506885 & Q02383 & 12 & $\begin{array}{l}\mathrm{NN}(5), \mathrm{NA} \\
(4), \mathrm{OA}(2), \\
\mathrm{ON}(1)\end{array}$ & & & $\begin{array}{l}\text { NN, NA, OA, } \\
\text { ON }\end{array}$ \\
\hline 3 & albumin preproprotein & 4502027 & P02768 & 12 & $\begin{array}{l}\mathrm{NN}(5), \mathrm{NA} \\
(4), \mathrm{OA}(2), \\
\mathrm{ON}(1)\end{array}$ & & & $\begin{array}{l}\text { NN, NA, OA, } \\
\text { ON }\end{array}$ \\
\hline 4 & lactotransferrin & 54607120 & P02788 & 12 & $\begin{array}{l}\mathrm{NN}(5), \mathrm{NA} \\
(4), \mathrm{OA}(2) \\
\mathrm{ON}(1)\end{array}$ & & & $\begin{array}{l}\text { NN, NA, OA, } \\
\text { ON }\end{array}$ \\
\hline 5 & $\begin{array}{l}\text { epididymal secretory protein } \\
\text { E1 precursor }\end{array}$ & 5453678 & P61916 & 12 & $\begin{array}{l}\mathrm{NN}(5), \mathrm{NA} \\
(4), \mathrm{OA}(2) \\
\mathrm{ON}(1)\end{array}$ & & & $\begin{array}{l}\mathrm{NN}, \mathrm{NA}, \mathrm{OA}, \\
\text { ON }\end{array}$ \\
\hline 6 & $\begin{array}{l}\text { extracellular matrix protein } 1 \\
\text { isoform } 1 \text { precursor }\end{array}$ & 221316614 & Q16610 & 12 & $\begin{array}{l}\mathrm{NN}(5), \mathrm{NA} \\
(4), \mathrm{OA}(2) \\
\mathrm{ON}(1)\end{array}$ & & & $\begin{array}{l}\text { NN, NA, OA, } \\
\text { ON }\end{array}$ \\
\hline 7 & $\begin{array}{l}\text { prosaposin isoform a } \\
\text { preproprotein }\end{array}$ & 11386147 & P07602 & 12 & $\begin{array}{l}\mathrm{NN}(5), \mathrm{NA} \\
(4), \mathrm{OA}(2) \\
\mathrm{ON}(1)\end{array}$ & & & $\begin{array}{l}\text { NN, NA, OA, } \\
\text { ON }\end{array}$ \\
\hline 8 & cathepsin D preproprotein & 4503143 & P07339 & 12 & $\begin{array}{l}\mathrm{NN}(5), \mathrm{NA} \\
(4), \mathrm{OA}(2) \\
\mathrm{ON}(1)\end{array}$ & & & $\begin{array}{l}\text { NN, NA, OA, } \\
\text { ON }\end{array}$ \\
\hline 9 & $\begin{array}{l}\text { prostate specific antigen } \\
\text { isoform } 1 \text { preproprotein }\end{array}$ & 4502173 & Q546G3 & 12 & $\begin{array}{l}\mathrm{NN}(5), \mathrm{NA} \\
(4), \mathrm{OA}(2) \\
\mathrm{ON}(1)\end{array}$ & & $\uparrow$ in $\mathrm{OA}$ & $\begin{array}{l}\text { NN, NA, OA, } \\
\text { ON }\end{array}$ \\
\hline 10 & zinc alpha-2-glycoprotein 1 & 4502337 & P25311 & 12 & $\begin{array}{l}\mathrm{NN}(5), \mathrm{NA} \\
(4), \mathrm{OA}(2) \\
\mathrm{ON}(1)\end{array}$ & & $\uparrow$ in ON & $\begin{array}{l}\text { NN, NA, OA, } \\
\text { ON }\end{array}$ \\
\hline 11 & clusterin isoform 1 & 42716297 & P10909 & 12 & $\begin{array}{l}\mathrm{NN}(5), \mathrm{NA} \\
(4), \mathrm{OA}(2), \\
\mathrm{ON}(1)\end{array}$ & Low in ON & $\downarrow$ in $\mathrm{ON}$ & $\mathrm{NN}, \mathrm{NA}, \mathrm{OA}$ \\
\hline 12 & mucin 6 , gastric & 151301154 & Q6W4X9 & 11 & $\begin{array}{l}\mathrm{NN}(4), \mathrm{NA} \\
(4), \mathrm{OA}(2) \\
\mathrm{ON}(1)\end{array}$ & & $\downarrow$ in NA & $\begin{array}{l}\text { NN, NA, OA, } \\
\text { ON }\end{array}$ \\
\hline 13 & cystatin S precursor & 4503109 & P01036 & 11 & $\begin{array}{l}\mathrm{NN}(4), \mathrm{NA} \\
(4), \mathrm{OA}(2), \\
\mathrm{ON}(1)\end{array}$ & Low in ON & $\downarrow$ in $N A, O A, O N$ & $\mathrm{NN}, \mathrm{NA}, \mathrm{OA}$ \\
\hline 14 & galectin 3 binding protein & 5031863 & Q08380 & 11 & $\begin{array}{l}\mathrm{NN}(5), \mathrm{NA} \\
(3), \mathrm{OA}(2), \\
\mathrm{ON}(1)\end{array}$ & $\begin{array}{l}\text { Low in } \mathrm{OA} \\
\text { and ON }\end{array}$ & $\downarrow$ in $\mathrm{OA}, \mathrm{ON}$ & $N N, N A$ \\
\hline 15 & $\begin{array}{l}\text { semenogelin I isoform b } \\
\text { preproprotein }\end{array}$ & 38049014 & P04279 & 10 & $\begin{array}{l}\mathrm{NN}(3), \mathrm{NA} \\
(4), \mathrm{OA}(2) \\
\mathrm{ON}(1)\end{array}$ & & $\uparrow$ in $\mathrm{OA}$ & $\begin{array}{l}\text { NN, NA, OA, } \\
\text { ON }\end{array}$ \\
\hline 16 & $\begin{array}{l}\text { prostatic acid phosphatase } \\
\text { precursor }\end{array}$ & 6382064 & P15309 & 10 & $\begin{array}{l}\mathrm{NN}(4), \mathrm{NA} \\
(3), \mathrm{OA}(2) \\
\mathrm{ON}(1)\end{array}$ & Low in ON & $\downarrow$ in NA, ON & $\mathrm{NN}, \mathrm{NA}, \mathrm{OA}$ \\
\hline 17 & cystatin C precursor & 4503107 & P01034 & 9 & $\begin{array}{c}\mathrm{NN}(4), \mathrm{NA} \\
(3), \mathrm{OA}(1), \\
\mathrm{ON}(1)\end{array}$ & & $\downarrow$ in $\mathrm{OA}$ & $\begin{array}{l}\text { NN, NA, OA, } \\
\text { ON }\end{array}$ \\
\hline 18 & $\begin{array}{l}\text { tissue inhibitor of } \\
\text { metalloproteinase } 1 \\
\text { precursor }\end{array}$ & 4507509 & Q6FGX5 & 8 & $\begin{array}{c}\mathrm{NN}(3), \mathrm{NA} \\
(3), \mathrm{OA}(1), \\
\mathrm{ON}(1)\end{array}$ & & $\uparrow$ in $\mathrm{ON}$ & $\begin{array}{l}\text { NN, NA, OA, } \\
\text { ON }\end{array}$ \\
\hline
\end{tabular}


Table 2 Detailed list of classification of 35 proteins based on their presence, abundance, and differential expression (Continued)

\begin{tabular}{|c|c|c|c|c|c|c|c|c|}
\hline 19 & $\begin{array}{l}\text { beta } 2 \text { microglobulin } \\
\text { precursor }\end{array}$ & 4757826 & P61769 & 8 & $\begin{array}{l}\mathrm{NN}(3), \mathrm{NA} \\
(3), \mathrm{OA}(1) \\
\mathrm{ON}(1)\end{array}$ & Low in $\mathrm{OA}$ & $\downarrow$ in $\mathrm{OA}$; Up in ON & $\mathrm{NN}, \mathrm{NA}, \mathrm{ON}$ \\
\hline 20 & DJ-1 protein & 31543380 & Q99497 & 6 & $\begin{array}{l}N N(2), N A \\
(3), O N(1)\end{array}$ & & $\uparrow$ in $N A$, ON & $\mathrm{NN}, \mathrm{NA}, \mathrm{ON}$ \\
\hline 21 & ankyrin repeat domain 11 & 56676397 & Q6UB99 & 4 & $\begin{array}{l}N A(1), O A \\
(2), O N(1)\end{array}$ & $\begin{array}{l}\text { Low in NA } \\
\text { and ON }\end{array}$ & $\downarrow$ in $\mathrm{OA}, \mathrm{ON}$ & OA \\
\hline 22 & orosomucoid 1 precursor & 167857790 & P02763 & 2 & $\begin{array}{l}\mathrm{NN}(2), \mathrm{NA} \\
(1)\end{array}$ & Low in NA & $\downarrow$ in NA & NN \\
\hline 23 & $\begin{array}{l}\text { serine proteinase inhibitor, } \\
\text { clade A, member } 1\end{array}$ & 50363217 & P01009 & 8 & $\begin{array}{c}\mathrm{NN}(3), \mathrm{NA} \\
(3), \mathrm{OA}(1), \\
\mathrm{ON}(1)\end{array}$ & & $\uparrow$ in $N A, O N$; $\downarrow$ in $\mathrm{OA}$ & $\mathrm{NA}, \mathrm{OA}, \mathrm{ON}$ \\
\hline 24 & transferrin & 4557871 & Q06AH7 & 6 & $\begin{array}{l}\mathrm{NN}(2), \mathrm{NA} \\
(3), \mathrm{OA}(1)\end{array}$ & $\begin{array}{l}\text { Low } \\
\text { abundant }\end{array}$ & $\uparrow$ in $N A, O A$ & NONE \\
\hline 25 & $\begin{array}{l}\text { secretory leukocyte } \\
\text { peptidase inhibitor precursor }\end{array}$ & 4507065 & P03973 & 5 & $\begin{array}{l}\mathrm{NN}(1), \mathrm{NA} \\
(3), \mathrm{OA}(1)\end{array}$ & $\begin{array}{l}\text { Low } \\
\text { abundant }\end{array}$ & $\uparrow$ in $N A, O A$ & NONE \\
\hline 26 & $\begin{array}{l}\text { ubiquitin and ribosomal } \\
\text { protein S27a precursor }\end{array}$ & 4506713 & P62979 & 4 & $\begin{array}{l}N N(2), N A \\
(1), O A(1)\end{array}$ & $\begin{array}{l}\text { Low } \\
\text { abundant }\end{array}$ & $\downarrow$ in $N A, O A$ & NONE \\
\hline 27 & $\begin{array}{l}\text { protein tyrosine } \\
\text { phosphatase, receptor type, } \\
\text { sigma isoform } 1 \text { precursor }\end{array}$ & 104487006 & Q13332 & 4 & $\begin{array}{l}\mathrm{NN}(1), N A \\
(2), O N(1)\end{array}$ & $\begin{array}{l}\text { Low } \\
\text { abundant }\end{array}$ & $\uparrow$ in $N A$, ON & NONE \\
\hline 28 & $\begin{array}{l}\text { acidic epididymal } \\
\text { glycoprotein-like } 1 \text { isoform } 1 \\
\text { precursor }\end{array}$ & 25121982 & P54107 & 3 & $\begin{array}{c}\mathrm{NN}(2), \mathrm{NA} \\
(1)\end{array}$ & $\begin{array}{l}\text { Low } \\
\text { abundant }\end{array}$ & $\downarrow$ in NA & NONE \\
\hline 29 & $\begin{array}{l}\text { prostaglandin H2 D- } \\
\text { isomerase }\end{array}$ & 32171249 & P41222 & 5 & $\begin{array}{l}\mathrm{NN}(2), N A \\
(2), \mathrm{OA}(1)\end{array}$ & $\begin{array}{l}\text { Low } \\
\text { abundant }\end{array}$ & & NONE \\
\hline 30 & cathepsin B preproprotein & 4503139 & P07858 & 6 & $\begin{array}{c}\mathrm{NN}(3), \mathrm{NA} \\
\text { (3) }\end{array}$ & $\begin{array}{l}\text { Low } \\
\text { abundant }\end{array}$ & & NONE \\
\hline 31 & $\begin{array}{l}\text { expressed in prostate and } \\
\text { testis }\end{array}$ & 19923082 & Q8WXA2 & 4 & $\begin{array}{l}\mathrm{NN}(2), \mathrm{NA} \\
(1), \mathrm{OA}(1)\end{array}$ & $\begin{array}{l}\text { Low } \\
\text { abundant }\end{array}$ & & NONE \\
\hline 32 & orosomucoid 2 & 4505529 & P19652 & 1 & $\mathrm{NN}(1)$ & $\begin{array}{l}\text { Low } \\
\text { abundant }\end{array}$ & & NONE \\
\hline 33 & CD177 molecule & 110735433 & Q8N6Q3 & 3 & $\begin{array}{l}\mathrm{NA}(1), \mathrm{OA} \\
(1), \mathrm{ON}(1 \mathrm{n} \\
\text { with (1)) }\end{array}$ & $\begin{array}{l}\text { Low } \\
\text { abundant }\end{array}$ & & NONE \\
\hline 34 & $\begin{array}{l}\text { carboxypeptidase E } \\
\text { preproprotein }\end{array}$ & 4503009 & P16870 & 9 & $\begin{array}{c}\mathrm{NN}(3), \mathrm{NA} \\
(3), \mathrm{OA}(2), \\
\mathrm{ON}(1)\end{array}$ & $\begin{array}{l}\text { Low in OA } \\
\text { and ON }\end{array}$ & & $\mathrm{NN}, \mathrm{NA}$ \\
\hline 35 & $\begin{array}{l}\text { fibronectin } 1 \text { isoform } 2 \\
\text { preproprotein }\end{array}$ & 47132551 & P02751 & 10 & $\begin{array}{c}\mathrm{NN}(4), \mathrm{NA} \\
(4), \mathrm{OA}(1), \\
\mathrm{ON}(1)\end{array}$ & Low in ON & & $\mathrm{NN}, \mathrm{NA}, \mathrm{OA}$ \\
\hline
\end{tabular}

$\mathrm{NN}=$ normal sperm count and normal morphology; $\mathrm{NA}=$ normal sperm count and abnormal morphology; ON = oligozoospermia and normal morphology; $\mathrm{OA}=$ oligozoospermia and abnormal morphology; number in the parenthesis indicates the number of samples.

proteins in the NA group was comparable in most of the cases to the NN group but was different from the $\mathrm{ON}$ and OA groups. The OA group showed only $\sim 15 \%$ of the proteins localized in the plasma membrane region compared to the other groups, with the maximum number of proteins $(\sim 20 \%)$ localized in the lysosomal and vacuolar regions. The ON group showed the least distribution of proteins in the nuclear region compared to the extracellular region.

The functional analysis of the significant proteins in each of the groups revealed that most of the proteins involved in the biological process were regulatory in function (Figure 4). Based on the distribution pattern of the regulatory proteins, the OA groups showed the least involvement of proteins $(60 \%)$ in regulation compared with $70 \%-75 \%$ seen in the NN, NA and ON groups. A smaller number of proteins were involved in other functional processes such as protein complex assembly, cell morphogenesis, membrane organization, protein maturation and trafficking in all the 4 groups. Interestingly, none of the proteins in the $\mathrm{ON}$ group were involved in any of these processes. Importantly, of all the major 


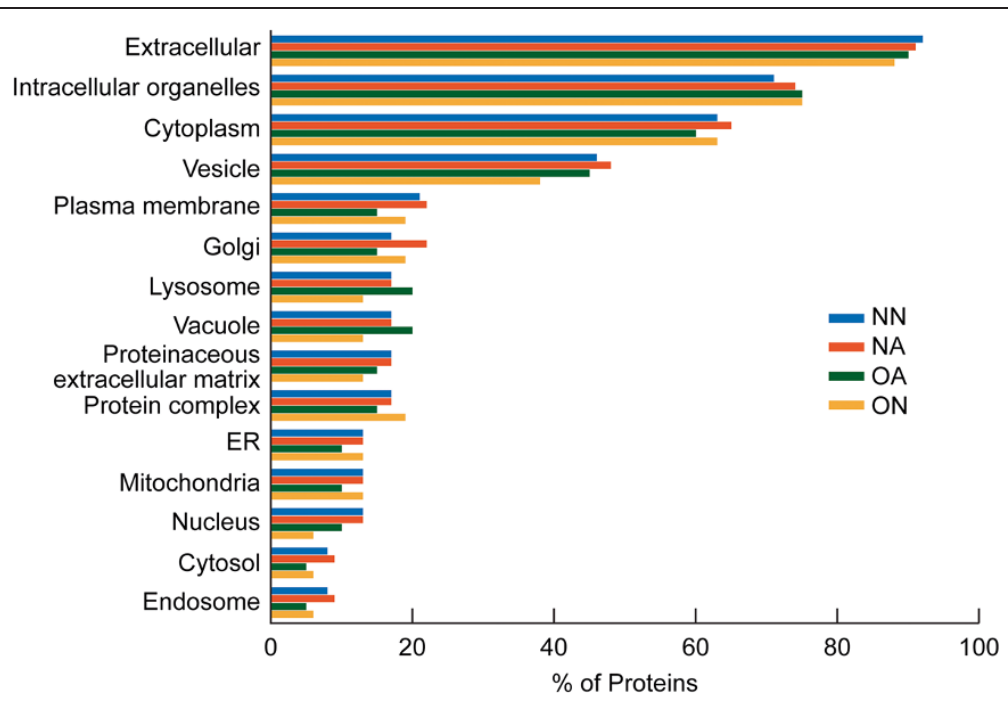

Figure 3 Functional annotations from consolidated findings using publicly available software tools (GO term mapper, GO term finder, UniProtKB, STRAP, BioGPS) and proprietary pathway software packages (Ingenuity Pathway Analysis and Metacore ${ }^{\mathrm{TM}}$ ) showing cellular distribution of significant proteins in NN, NA, OA, and ON groups.

processes represented, the OA groups showed the lowest distribution of signal transduction proteins $(15 \%)$ and had little or no role in neurological system processing, membrane organization and protein maturation.

\section{Comparison of cellular distribution and biological} processes amongst the common, DEP, and low abundant proteins

A detailed evaluation of the cellular localization of the common, DEP and low abundant proteins is shown in Figure 5. A higher distribution of the common proteins was seen in the majority of cellular compartments compared to DEP and low abundance proteins. The extracellular region showed the highest distribution (91\%) of the common proteins whereas they were absent in the ribosomal and endosomal regions. Higher distribution of differentially expressed proteins was seen in the cytosolic and Golgi regions compared to the common or low abundance proteins. The low abundant proteins were absent in the protein complex and secretory granular region but their localization was found to be high in the nuclear and endosomal regions.

A comparative analysis of the proteins involved in various biological processes in the three groups are

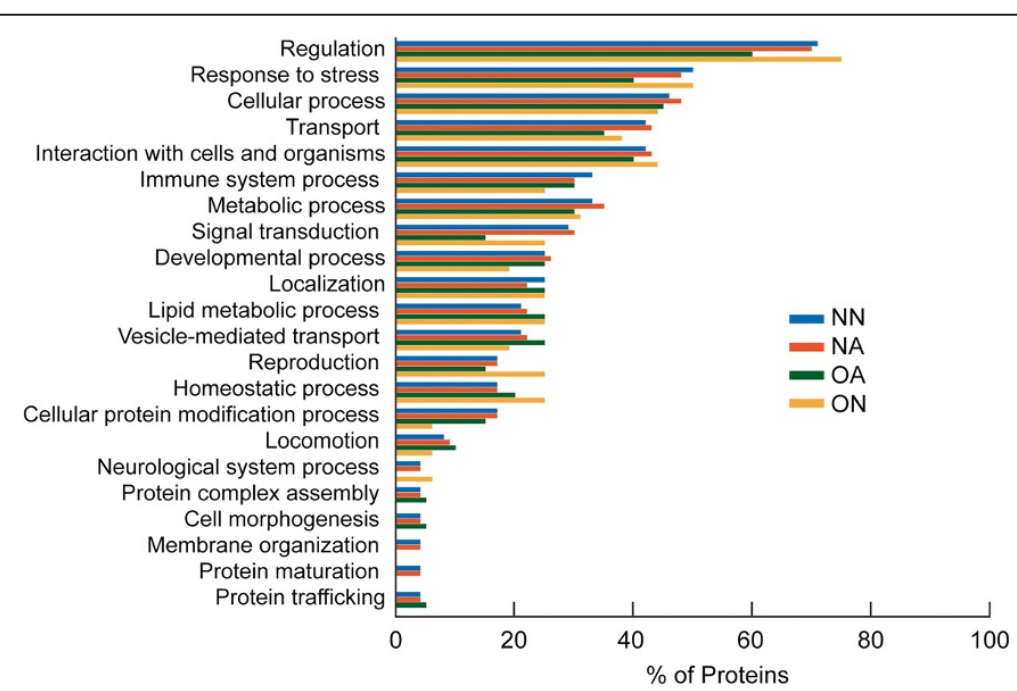

Figure 4 Functional annotations from consolidated findings using publicly available software tools (GO term mapper, GO term finder, UniProtKB, STRAP, BioGPS) and proprietary pathway software packages (Ingenuity Pathway Analysis and Metacore ${ }^{\mathrm{TM}}$ ) showing biological processes of significant proteins in NN, NA, OA and ON group. 


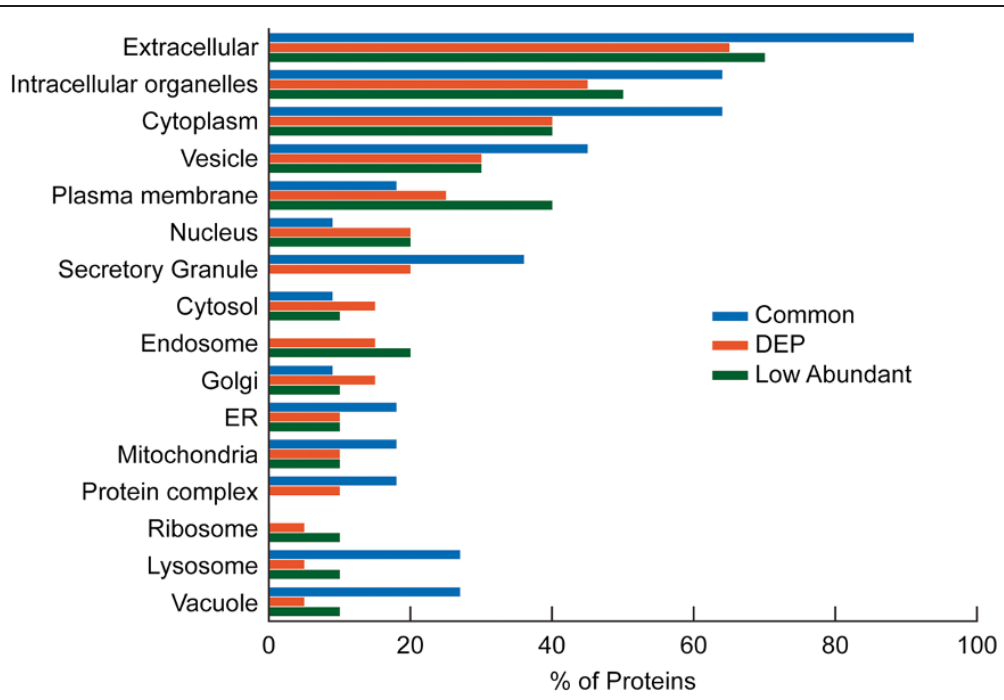

Figure 5 Functional annotations from consolidated findings using publicly available software tools (GO term mapper, GO term finder, UniProtKB, STRAP, BioGPS) and proprietary pathway software packages (Ingenuity Pathway Analysis and Metacore ${ }^{\mathrm{TM}}$ ) showing comparison of cellular distribution amongst the proteins in Common, DEP, and Low abundant category.

shown in Figure 6. The proteins commonly expressed in all 4 groups played a significant role in many of the biological processes such as cellular development, molecular transport, and stress response, interactions with cells and organisms, cellular processes and in processes relating to the immune system. Compared with the common proteins, DEP were comparable for the regulatory processes, but were reduced in all biological processes. Higher distribution was seen in protein metabolic process, vesicle mediated transport, defense response and cellular protein modification process. The low abundant proteins were seen to be involved mainly in protein metabolism, vesicle-mediated transport and defense response.

Pathways and network analysis using IPA and metacore ${ }^{\mathrm{TM}}$ Based on the dataset derived from common, DEP and low abundance proteins, pathways, biological functions and networks of interactions were derived utilizing the two proprietary pathway packages, IPA and Metacore ${ }^{\mathrm{Tm}}$. The important processes affected by common proteins were lipid metabolism (epididymal secretory protein E1 precursor, prosaposin isoform A preprotein, clusterin isoform 1, lactotransferrin and cathepsin D preprotein),

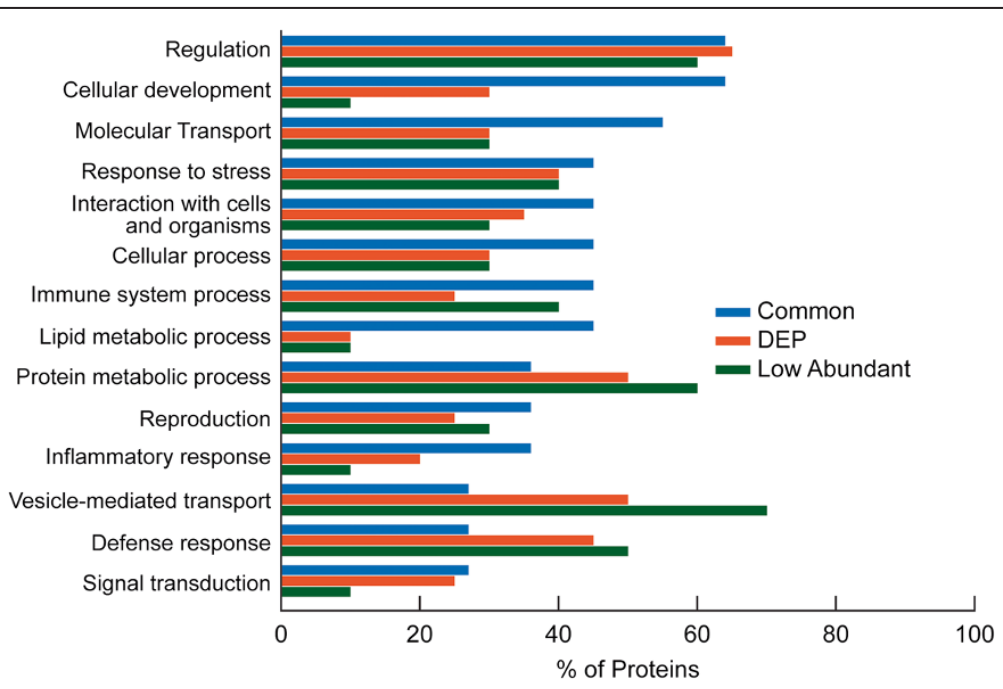

Figure 6 Functional annotations from consolidated findings using publicly available software tools (GO term mapper, GO term finder, UniProtKB, STRAP, BioGPS) and proprietary pathway software packages (Ingenuity Pathway Analysis and Metacore ${ }^{\mathrm{TM}}$ ) showing Comparison of Biological Processes amongst the proteins in Common, DEP, and Low abundant category. 
cell death and survival (cathepsin D preprotein, lactotransferrin, clusterin isoform 1, prosaposin isoform A preprotein and prostate specific antigen isoform 1 preprotein), and cellular development (clusterin isoform 1 , prostate specific antigen isoform 1 preprotein, lactotransferrin, extracellular matrix protein 1 isoform 1 precursor, cathepsin D preprotein and epididymal secretory protein E1 precursor).

The important processes affected by DEP showed a higher involvement in carbohydrate metabolism and nephrosis (ankyrin repeat domain 11, beta 2 microglobulin (B2MG) precursor, clusterin isoform 1, cystatin C precursor, prostate specific antigen isoform 1 preprotein, DJ-1 protein, protein tyrosine phosphatase, receptor type, sigma isoform 1 precursor, transferrin). The major pathways involved are proteolysis (extracellular matrix; ECM), remodeling and connective tissue degradation, immune response, clathrin-mediated endocytosis signaling, lipid antigen presentation by CD1, and intrinsic prothrombin activation pathway. Similarly, in the low abundant proteins the top biological functions included the cellular development, growth proliferation, DNA replication, recombination, and repair (prostaglandin $(\mathrm{H} 2)$ D-isomerase, protein tyrosine phosphatase, receptor type, sigma isoform 1 precursor and transferrin).

We also studied the major biological functions of the DEP in each of the 3 groups and found that free radical scavenging was the topmost function in the NA group, while cell-to-cell signaling and interaction were seen in all 3 groups. Genes that encode for 7 differentially expressed proteins (cysteine-rich secretory protein 1, clusterin, prostatic acid phosphatase (PAP), mucin 6, prostate specific antigen (PSA), zinc alpha-2-glycoprotein 1, and DJ-1) are known to be regulated by androgen receptor. The transcriptional network showed the activation of prostate induction by the androgen receptor signaling pathway. DJ-1 protein, protein tyrosine phosphatase, receptor type, sigma isoform 1 precursor and transferrin were observed to interact with other proteins in the pathway database and affect processes related to cellular function and maintenance. Similarly, in the OA group, prostate specific antigen isoform 1 preprotein and transferrin formed the topmost network, encompassing key processes such as gene expression, tissue morphology and cell cycle. The ON group showed immunological disease, antigen presentation, cell-to-cell signaling and interaction (B2MG precursor, DJ-1 protein, receptor type, sigma isoform 1 precursor) as the key processes affected in its topmost network

\section{Discussion}

Seminal plasma is a mixture of secretions of several male accessory glands, including prostate, seminal vesicles, epididymis and Cowper's gland. Prostate gland is a major contributor to seminal plasma. It is a very rich source of protein with concentration ranges from 35 to $55 \mathrm{~g} / \mathrm{l}$ $[9,10]$. It provides a safe environment for spermatozoa to carry out their physiological functions. Understanding the protein profile of human seminal plasma is important because it has a profound impact on sperm physiology and thus may affect sperm functioning [31].

In this novel study, we identified 35 proteins based on SEQUEST scoring in the seminal plasma of men with varying semen parameters and categorized them into common, differentially expressed, and low abundant proteins. The large variation in the number of proteins identified by any given technique depends mainly on the sample preparation and mass spectrometry technology available [32-36]. Recently, the LTQ-Orbitrap mass spectrometer has become the cutting-edge instrument for LC/MDS/MS based approaches to characterize the seminal proteome. In our study, we used in-solution digestion of proteins with the online LC-MS system. Seminal plasma from different subsets was pooled to form 4 distinct study groups. There are numerous studies in the proteomic literature that refer to the benefits of pooling samples where it may not be feasible to analyze individual samples due to limitations of the sample or the study design $[8,17,37,38]$.

Of the 11 proteins found in all the samples, 9 were associated with sperm function, and the common proteins comprised the majority of the secretions of the prostate gland, the seminal vesicles and epididymis. Some of the proteins or their isoforms detected in the seminal plasma were zinc alpha-2-glycoprotein 1, clusterin, lactotransferrin, prostate specific antigen. These were similar to those reported by Utleg et al. [39].

Prostate specific antigen is a serine protease that cleaves semenogelin by hydrolysis and thus liquefies the semen coagulum and facilitates sperm motility and capacitation $[40,41]$. Our study showed that prostate specific antigen isoform I preprotein was one of the common proteins, thus indicating its importance in all the 4 groups. Prolactin-induced protein (PIP) and Sg II are important common proteins that have a profound impact on sperm physiology. PIP has specificity to fibronectin and constitutes about $1 \%$ of seminal coagulum [42]. It may play a vital role in fibronectin breakdown during liquefaction. Viscous samples have been reported to show reduced amounts of PIP and PIP precursor, which may also be a contributory factor towards incomplete liquefaction [43]. Both Sg I and II are the major proteins of the coagulum. They represent $20-40 \%$ of the seminal plasma proteins. Studies have shown increased $\mathrm{Sg}$ concentrations in asthenozoospermic men [44,45]. Our study showed that both prolactin and semenogelin II were in all samples but they were not differentially expressed, indicating that men with low sperm count or 
abnormal morphology may not be affected by these proteins - a conclusion also made by Milardi et al. [18].

Epididymal secretory protein E I precursor, albumin preprotein, lactotransferrin, extracellular matrix protein E1 precursor, prosaposin isoform a preprotein, cathepsin D preprotein were some of the commonly expressed proteins that were not differentially expressed in any of the groups, suggesting that these proteins may not play a significant role in sperm concentration or morphology.

The highest percentage of the common proteins was seen in the extracellular region (Figure 5). Human seminal plasma proteins can bind to sperm surface proteins in the ejaculate and form a protective layer around the spermatozoon [12] as well as a sperm reservoir in the oviduct [46]. It is likely that the extracellular origin of most of the common proteins may play a key role in the binding activity of the proteins. The absence of common proteins in the ribosomal and endosomal region (Figure 5) suggests a relatively low involvement in protein metabolism, as also seen by the low distribution of common proteins in the 'protein metabolic process' category, (Figure 6). Zinc alpha-2 glycoprotein and clusterin play a role in signal transduction while lactotransferrin is a transport and structural protein [39]. Prostate specific antigen has been shown to have enzymatic activity. Our results show a high distribution of signal transducing protein among the common proteins, suggesting the importance of clusterin, isoform 1 and zinc alpha-2 glycoprotein 1 (Figure 6). This was also confirmed from the pathway and network analysis, which also highlighted the role these proteins play in molecular transport, cell death and survival and lipid metabolism.

A clear overlap was observed for some of the differentially expressed proteins. These included the prostate specific antigen isoform 1 preprotein, zinc alpha 2 glycoprotein 1 , and clusterin isoform 1 . While semenogelin II precursor was seen in common proteins, the semenogelin I isoform b preprotein was found to be upregulated in the OA group. This suggests that it may contribute to the low motility seen in this group compared to other groups.

Clusterin isoform was downregulated in the $\mathrm{ON}$ group. This is an interesting finding, given that clusterin isoform 1 has been shown to be downregulated in prostate cancer. The proteome of the seminal fluid is largely attributed to secretions from the prostate gland, and approximately $10 \%$ is contributed by the testis and the epididymis [8].

Prostate gland is a major contributor to seminal plasma. Furthermore, one of the proteins - prostatic acid phosphatase (PAP) was significantly increased in azoospermic men compared to oligozoospermic men and asthenozoospermic men [10]. In our study, PAP levels were down regulated in the NA and ON groups. PAP levels have also been reported to correlate with sperm concentration
[47-49]. Patients with severe oligozoospermia $\left(<1 \times 10^{6}\right)$ were also shown to have increased levels of seminal PAP [50]. PAP is produced in the prostate gland and is present in the seminal fluid at a concentration of $1 \mathrm{mg} / \mathrm{mL}$. It is an important tumor marker and acts as a negative growth regulator in prostate cancer [51].

A proteomic analysis of seminal fluid, rather than blood, has been proposed as as a better starting point to identify changes that may serve as specific and sensitive markers of prostate dysfunction [17]. These authors identified more than 100 proteins such as PSA, semenogelin I and II, clusterin etc. which have been shown to affect sperm quality.

The increased expression of semenogelin I in the OA group suggests that the accessory gland secretions have a profound impact on oligozoospermic men with abnormal morphology. Wang et al. reported semenogelin I and mucin were not differentially expressed and therefore had no effect in asthenozoospermic men [21]. Our study also included the differentially expressed proteins, especially DJ-1 secreted from the testis, epididymis and prostate $[39,52]$. DJ-1 has a high level of expression in the testis. We found DJ-1 to be overexpressed in the NA and ON groups. We also documented that orosomucoid 1 precursor was downregulated in the NA group whereas expression of orosomucoid 2 was comparable in all groups, though it was present in low abundance. However, Wang et al. reported the overexpression of orosomucoid 1 and orosomucoid 2 in asthenozoospermic patients [21]. These proteins have also been found in high abundance in post vasectomy patients [8].

B2MG was found to be under-expressed in OA while over-expressed in the ON samples. B2MG is present in all nucleated cells. It is one of the two polypeptide chains of the major histocompatiblity complex (MHC) class I molecule. In humans B2MG is coded by the B2M gene. It is a marker of cellular immune system. It is a naturally occurring protein and can detect certain types of tumor cells in the blood and kidney, and some inflammatory and autoimmune disorders [53,54]. In our study as well as that reported by Fung et al. [17], many of the proteins in the seminal plasma were identified to be forerunners of prostate disease, suggesting a pathogenic role for B2MG [55,56]. Similarly high levels of B2MG were reported in the seminal plasma of azoospermic men compared to controls $[10,57,58]$. An inverse correlation was reported between B2MG levels in seminal fluid and sperm count [10].

Similary, we reported the underexpression of galectin 3 binding protein in oligozoospermic group. Galectin-3 is a carbohydrate-binding protein whose expression level has been shown to correlate with metastatic potential in a number of different types of tumors. Galectin-3 is downregulated in prostate cancer. The altered 
downregulation pattern of galectin-3 observed between tumor stages suggests different roles for galectin-3 in the progression of prostate cancer [59].

TIMP 1 can inhibit tumor growth, invasion and metastasis through their matrix metalloproteinases (MMP) inhibitory activity $[60,61]$. TIMPs play an inhibitory role, and any imbalance between the two may result in progression of the disease [62]. TIMP was found to be overexpressed in the ON group.

Amongst the proteins that were uniquely underexpressed in the OA group was ankyrin repeat domain 11 (ANKRD11). Ankyrins function as adaptor proteins $[63,64]$ and play a vital role in membrane skeleton organization, ionic transport, maintenance of cell polarity as well as cell-cell adhesion regulation. Data suggest that ANKRD11 may act as a tumor suppressor [65]. It's presence in the semen samples has not been well documented, but it is likely that its overexpression in oligozoospermic men may play a role in apoptosis. Clusterin isoform 1 can be both pro- and antiapoptotic depending upon the isoform expressed $[66,67]$. It plays a key role in signal transduction and is involved in apoptosis of spermatocytes, sperm maturation, and spermiation. Low signal transducing proteins were seen in the OA group compared with the other groups, as shown in Figure 4.

Compared with the proteins involved in stress response, as elucidated from GO annotations (Figure 4), the NA and ON groups had a higher distribution of stress proteins such as DJ-1 whereas a lower distribution of this protein was seen in OA group. DJ-1 protein is a multifunctional, highly conserved antioxidant protein and is upregulated in hyperglycemia $[68,69]$. It is mainly involved in the control of oxidative stress and is downregulated in the seminal plasma of asthenozoospermic men [21]. DJ-1 is activated in stress conditions, but with higher levels of stress (as seen in OA), there is depletion of antioxidant levels and low expression of DJ-1 protein. Furthermore, the major biological function that comes into focus through IPA in the NA group is free-radical scavenging activity. This further supports the fact that DJ-1 was activated in the NA group. Significant proteins were distributed in the lysosomal and vacuolar regions in higher amounts in the OA group (Figure 3), suggesting that proteins with phagocytic activity may be activated in stress conditions. Previous studies have reported reduced levels of DJ-1 in sperm in response to toxic exposure of male rats to ornidazole and epichlorhydrin [70].

Utleg et al. categorized prostatic acid phosphatase (PAP) precursor as an enzymatic protein, and the presence of this protein in our study suggests that it plays a similar role [39]. The distribution pattern of immune system response in all the groups is shown in Figure 4. It is likely that B2MG is the major protein in immune response and that low levels of this protein are seen in stress conditions. Low distribution of B2MG in DEP compared to normal and low abundant proteins further suggests that in addition to B2MG, there are other proteins that also play a key role in immune system processes. We further validated this observation from the pathway analysis, which showed that that the common protein prosaposin isoform, a preprotein, is involved in lipid antigen presentation by CD1.

We observed overlapping of differentially expressed proteins with the low abundant proteins in our study. These included transferrin, secretory leukocyte peptidase inhibitor precursor, ubiquitin and ribosomal protein S27a precursor, protein tyrosine phosphatase, receptor type, sigma isoform 1 precursor and acidic epidiymal glycoprotein- like 1 isoform 1 precursor. Of these proteins, protein tyrosine phosphatase, receptor type, sigma isoform 1 precursor, acidic epididymal glycoprotein-like isoform 1 precursor were amongst the low abundant proteins. Protein tyrosine phosphatase, receptor type, sigma isoform 1 precursor were upregulated while acidic epididymal glycoprotein-like isoform 1 precursor was down regulated in the NA group. The acidic epididymal glycoprotein like I isoform I precursor is a member of the cysteine - rich secretory protein (CRISP) family and is encoded by the gene CRISP-I. It is expressed in the epididymis and is secreted into the epididymal lumen. It binds to the post acrosomal region of the head, where it may play a role in sperm-egg fusion. The reported low abundance of acidic epididymal glycoprotein like I isoform I precursor protein is concordant with the findings of Batruch et al. who also reported its low abundance in the seminal plasma of post vasectomy patients compared to controls [8].

Transferrin is one of the serum proteins that has been characterized in the seminal plasma, but its role in male infertility is unclear [20]. Our study showed this protein was present in low levels in the NN group but was up regulated in NA and OA groups. Prostaglandin H2 D isomerase, cathepsin $\mathrm{B}$ preprotein, orosomucoid 2 and the CD177 molecule were the low abundant proteins that were not differentially expressed in any of the groups. In our study, CD177 was absent in the NN group but present in all the other groups although they were not differentially expressed. Our findings are consistent with previous publications that reported low concentrations of CD177 in fertile men (control samples) compared to postvasectomy men [8] but are contrary to the findings of Wang et al. who reported upregulation of CD177 in asthenozoospermic patients [21]. Cathepsin B preprotein was present in the NN and NA groups, showing its specificity to the normal sperm count while prostaglandin $\mathrm{H} 2$ $\mathrm{D}$ isomerase was absent in the $\mathrm{ON}$ group. Cathepsin $\mathrm{B}$ preprotein found in the lysosomal region is a thiol 
protease believed to participate in intracellular degradation. It has also been implicated in tumor invasion and metastasis. The prostaglandin (H2) D-isomerase is expressed in the testis, epididymis and prostate and is secreted into the seminal fluid. It binds small non-substrate lipophilic molecules and may act as a scavenger for harmful hydrophobic molecules. The prostaglandin (H2) Disomerase and cathepsin B protein are potentially involved in biological processes such as vesicle-mediated transport and defense response. The low abundant proteins showed a marked distribution in the extracellular region and may play a regulatory role. The major pathways in which the low abundant proteins were involved were prostanoid biosynthesis and eicosanoid signaling and acute phase response signaling, but the distribution of signal transduction proteins was decreased in low abundant proteins.

\section{Conclusions}

In the present study, we have identified proteins that are common, unique, and differentially expressed in 4 study groups. Twenty proteins were differentially expressed in the seminal plasma of men with poor sperm quality. We have highlighted the distribution pattern of these proteins in cell organelles and described their biological processes. We have also illustrated the high involvement of proteins in cellular development signal transduction. The overexpression or underexpression of these proteins in the 4 groups illustrates their role in male infertility. Our findings from the bioinformatic analysis shows that stress proteins such as DJ-1 are differentially regulated and expressed in the different study groups, suggesting that some of these proteins may serve as a potential biomarkers in identifying the mechanistic role in men with poor sperm quality.

\section{Competing interests}

The authors declare that they have no competing interests.

\section{Authors' contributions \\ RS participated in the study conception/design, review of the data and writing of the manuscript and final approval. BW, SY and BG contributed to data interpretation and participated in the paper redaction; GM participated in the review of the data and writing of the manuscript. AA contributed to the study design, and review of the data. RJ participated in organizing the subject information and review of the study findings. ES provided the subjects and participated in the study design. All authors read and approved the final manuscript.}

\section{Acknowledgements}

This study was supported by Cleveland Clinic, Research Program Committee. Authors wish to thank the Cleveland Clinic Andrology laboratory personnel for their help with scheduling of subjects used in this study. This research project was supported in part by funds from the Cleveland Clinic Research Program Committee and the Center for Reproductive Medicine. Visit of GM supported in part by the INSPIRE fellowship from the Department of Science and Technology, New Delhi, India.

\section{Author details}

'Center for Reproductive Medicine, Glickman Urological and Kidney Institute, Cleveland Clinic, Cleveland, OH, USA. ${ }^{2}$ Center for Cellular and Molecular Biology, Hyderabad, Andhra Pradesh, India. ${ }^{3}$ Bioinformatics Core Services, Lerner Research Institute, Cleveland Clinic, Cleveland, OH, USA. ${ }^{4}$ Proteomics Core Services, Lerner Research Institute, Cleveland Clinic, Cleveland, OH, USA. ${ }^{5}$ Molecular Biotechnology Core lab, Lerner Research Institute, Cleveland Clinic, Cleveland, OH, USA. ${ }^{6}$ Permanent Address: Ravenshaw University, Cuttack, Odisha, India.

Received: 15 January 2013 Accepted: 22 March 2013

Published: 11 May 2013

References

1. The Practice Committee of the American Society for Reproductive Medicine: Diagnostic evaluation of the infertile male: a committee opinion. Fertil Steril 2012, 98:294-301.

2. Kruger TF, Menkveld R, Stander FS, Lombard CJ, Van der M, van Zyle JA, Smith K: Sperm morphologic features as a prognostic factor in in vitro fertilization. Fertil Steril 1986, 46:1118-1123.

3. Kruger TF, Acosta AA, Simmons KF, Swanson RJ, Matta JF, Veeck LL, Morshedi M, Brugo S: New method of evaluating sperm morphology with predictive value for human in vitro fertilization. Urology 1987, 30:248-251.

4. Guzick DS, Overstreet JW, Factor-Litvak P, Brazil CK, Nakajima ST, Coutifaris C, Carson SA, Cisneros P, Steinkampf MP, Hill JA, Xu D, Vogel DL: Sperm morphology, motility, and concentration in fertile and infertile men. N Engl J Med 2001, 345:1388-1393.

5. Agarwal A, Sharma RK, Nallella KP, Thomas AJ Jr, Alvarez JG, Sikka SC: Reactive oxygen species as an independent marker of male factor infertility. Fertil Steril 2006, 86:878-885.

6. Saleh RA, Agarwal A, Nada EA, El-Tonsy MH, Sharma RK, Meyer A, Nelson DR, Thomas AJ: Negative effects of increased sperm DNA damage in relation to seminal oxidative stress in men with idiopathic and male factor infertility. Fertil Steril 2003, 79:1597-1605.

7. Sharma R, Agarwal A: Spermatogenesis: an overview. In Human sperm chromatin: structure and function. Sperm chromatin. Biological and clinical applications in male infertility and assisted reproduction. Edited by Zini A, Agarwal A. Springer Science + Business Media, LLC; 2012:19-44.

8. Batruch I, Lecker I, Kagedan D, Smith CR, Mullen BJ, Grober E, Lo KC, Diamandis EP, Jarvi KA: Proteomic analysis of seminal plasma from normal volunteers and post-vasectomy patients identifies over 2000 proteins and candidate biomarkers of the urogenital system. J Proteome Res 2011, 10:941-953.

9. Pilch B, Mann M: Large-scale and high-confidence proteomic analysis of human seminal plasma. Genome Biol 2006, 7(5):R40.

10. Davalieva K, Kiprijanovska S, Noveski P, Plaseski T, Kocevska B, Broussard C, Plaseska-Karanfilska D: Proteomic analysis of seminal plasma in men with different spermatogenic impairment. Andrologia 2012, 44:256-264.

11. Primakoff $P$, Myles DG: Penetration, adhesion, and fusion in mammalian sperm-egg interaction. Science 2002, 296:2183-2185.

12. Varilová T, Seménková H, Horák P, Madera M, Pacáková V, Tichá M, Stulík K Affinity liquid chromatography and capillary electrophoresis of seminal plasma proteins. J Sep Sci 2006, 29:1110-1115.

13. Kelly RW: Immunosuppressive mechanisms in semen: implications for contraception. Hum Reprod 1995, 10:1686-1693.

14. Nishimune $Y$, Tanaka $\mathrm{H}$ : Infertility caused by polymorphisms or mutations in spermatogenesis-specific genes. J Androl 2006, 27:326-334.

15. Mengual L, Ballescá JL, Ascaso C, Oliva R: Marked differences in protamine content and P1/P2 ratios in sperm cells from percoll fractions between patients and controls. J Androl 2003, 24:438-447.

16. Aoki WW, Moskovtsev SI, Willis J, Liu L, Mullen JB, Carrell DT: DNA integrity is compromised in protamine-deficient human sperm. J Androl 2005, 26:741-748.

17. Fung KY, Glode LM, Green S, Duncan MW: A comprehensive characterization of the peptide and protein constituents of human seminal fluid. Prostate 2004, 61:171-181.

18. Milardi D, Grande G, Vincenzoni F, Messana I, Pontecorvi A, De Marinis L, Castagnola M, Marana R: Proteomic approach in the identification of fertility pattern in seminal plasma of fertile men. Fertil Steril 2012, 97:67-73. 
19. Starita-Geribaldi M, Poggioli S, Zucchini M, Garin J, Chevallier D, Fenichel P, Pointis G: Mapping of seminal plasma proteins by two dimensional gel electrophoresis in men with normal and impaired spermatogenesis. Mol Hum Reprod 2001, 7:715-722

20. Yamakawa K, Yoshida K, Nishikawa H, Kato T, Iwamoto T: Comparative analysis of interindividual variations in the seminal plasma proteome of fertile men with identification of potential markers for azoospermia in infertile patients. J Androl 2007, 28:858-865.

21. Wang J, Wang J, Zhang HR, Shi HJ, Ma D, Zhao HX, Lin B, Li RS: Proteomic analysis of seminal plasma from asthenozoospermia patients reveals proteins that affect oxidative stress responses and semen quality. Asian J Androl 2009, 11:484-491.

22. World Health Organization: WHO laboratory manual for the examination and processing of human semen. 5th edition. Cambridge: World Health Organization; 2010

23. Hamada A, Sharma R, du Plessis SS, Willard B, Yadav SP, Sabanegh E, Agarwal A: Two-dimensional differential in-gel electrophoresis-based proteomics of male gametes in relation to oxidative stress. Fertil Steril 2013.

24. Boyle E, Weng S, Gollub J, Jin H, Botstein D, Cherry JM, Sherlock G: GO: TermFinder-open source software for accessing gene ontology information and finding significantly enriched gene ontology terms associated with a list of genes. Bioinformatics 2004, 20:3710-3715.

25. GO term mapper. http://go.princeton.edu/cgi-bin/GOTermMapper.

26. The UniProt Consortium: Reorganizing the protein space at the universal protein resource (UniProt). Nucleic Acids Res 2012, 40:D71-D75

27. Bhatia VN, Perlman DH, Costello CE, McComb ME: Software tool for researching annotations of proteins: open-source protein annotation software with data visualization. Anal Chem 2009 81:9819-9823.

28. Chunlei W, Camilo O, Jason B, Marc L, James G, Serge B, Hodge CL, James H, Jeff J, Huss JW, et al: BioGPS: an extensible and customizable portal for querying and organizing gene annotation resources. Genome Biol 2009, 10:R130.

29. Ingenuity pathway analysis (IPA) from ingenuity ${ }^{\oplus}$ systems. Website Title: www. ingenuity.com

30. Metacore ${ }^{\mathrm{TM}}$ from GeneGo Inc. Website: www.genego.com.

31. Frenette G, Girouard J, Sullivan R: Comparison between epididymosomes collected in the intraluminal compartment of the bovine caput and cauda epididymidis. Biol Reprod 2006, 75:885-890.

32. Mirza SP, Olivier M: Methods and approaches for the comprehensive characterization and quantification of cellular proteomes using mass spectrometry. Physiol Genomics 2008, 33:3-11.

33. Claverol S, Burlet-Schiltz O, Gairin JE, Monsarrat B: Characterization of protein variants and post-translational modifications: ESI-MSn analyses of intact proteins eluted from polyacrylamide gels. Mol Cell Proteomics 2003, 2:483-493.

34. Guthals A, Bandeira N: Peptide identification by tandem mass spectrometry with alternate fragmentation modes. Mol Cell Proteomics 2012, 11:550-557.

35. Liao $\Pi$, Xiang Z, Zhu WB, Fan LQ: Proteome analysis of round-headed and normal spermatozoa by 2-D fluorescence difference gel electrophoresis and mass spectrometry. Asian J Androl 2009, 11:683-693.

36. VerBerkmoes NC, Bundy JL, Hauser L, Asano KG, Razumovskaya J, Larimer F, Hettich RL, Stephenson JL Jr: Integrating "top-down" and "bottom-up" mass spectrometric approaches for proteomic analysis of shewanella oneidensis. J Proteome Res 2002, 1:239-52.

37. Rolland AD, Lavigne R, Dauly C, Calvel P, Kervarrec C, Freour T, Evrard B, Rioux-Leclercq N, Auger J, Pineau C: Identification of genital tract markers in the human seminal plasma using an integrative genomics approach. Hum Reprod 2013, 28:199-209.

38. Kagedan D, Lecker I, Batruch I, Smith C, Kaploun I, Lo K, Grober E, Diamandis EP, Jarvi KA: Characterization of the seminal plasma proteome in men with prostatitis by mass spectrometry. Clin Proteomics 2012, 9:2.

39. Utleg AG, Yi EC, Xie T, Shannon P, White JT, Goodlett DR, Hood L, Lin B: Proteomic analysis of human prostasomes. Prostate 2003, 56:150-161.

40. Mitra A, Richardson RT, O'Rand MG: Analysis of recombinant human semenogelin as an inhibitor of human sperm motility. Biol Reprod 2010, 82:489-496.

41. Robert M, Gibbs BF, Jacobson E, Gagnon C: Characterization of prostatespecific antigen proteolytic activity on its major physiological substrate, the sperm motility inhibitor precursor/semenogelin I. Biochemistry 1997, 36:3811-3819.

42. Lilja H, Abrahamsson PA, Lundwall A: Semenogelin, the predominant protein in human semen. Primary structure and identification of closely related proteins in the male accessory sex glands and on the spermatozoa. J Biol Chem 1989, 264:1894-1900.

43. Thacker S, Yadav SP, Sharma RK, Kashou A, Willard B, Zhang D, Agarwal A: Evaluation of sperm proteins in infertile men: a proteomic approach. Fertil Steril 2011, 95:2745-2748.

44. Malm J, Hellman J, Magnusson H, Laurell CB, Lilja H: Isolation and characterization of the major gel proteins in human semen, semenogelin I and semenogelin II. Eur J Biochem 1996, 238:48-53.

45. Zhao C, Huo R, Wang FQ, Lin M, Zhou ZM, Sha JH: Identification of several proteins involved in regulation of sperm motility by proteomic analysis. Fertil Steril 2007, 87:436-438.

46. Jansen S, Ekhlasi-Hundrieser M, Töpfer-Petersen E: Sperm adhesion molecules: structure and function. Cells Tissues Organs 2001, 168:82-92.

47. Vaubourdolle M, Clavel JP, Gonzales J, Galli A: Evaluation of acid phosphatase isoenzymes in seminal fluid from normozoospermic, oligozoospermic, azoospermic and asthenoteratozoospermic men. Andrologia 1985, 17:598-604.

48. Dave BN, Rindani TH: Acid phosphatase activity in human semen. Int J Fertil 1988, 33:45-47.

49. Ziyyat A, Barraud-Lange V, Sifer C, Ducot B, Wolf JP, Soufir JC: Paradoxical increase of sperm motility and seminal carnitine associated with moderate leukocytospermia in infertile patients. Fertil Steril 2008 90:2257-2263.

50. Singh G, Adaikan PG, Ng YK: Is seminal prostatic acid phosphatase a reliable marker for male infertility? Singapore Med J 1996, 37:598-599.

51. Ostrowski W: In Male accessory Sex glands. Edited by Spring-Mills E, Hafez E. Amsterdam: Elsevier/North-Holland Biomedical Press; 1980:pp. 197-213.

52. Li R, Guo Y, Han BM, Yan X, Utleg AG, Li W, Tu LC, Wang J, Hood L, Xia S, Lin B: Proteomics cataloging analysis of human expressed prostatic secretions reveals rich source of biomarker candidates. Clin Appl 2008, 2:543-555

53. Cooper EH, Plesner T: Beta-2-microglobulin review: its relevance in clinical oncology. Med Pediatr Oncol 1980, 8:323-334.

54. Di Giovanni S, Valentini G, Carducci P, Giallonardo P: Beta-2-microglobulin is a reliable tumor marker in chronic lymphocytic leukemia. Acta Haematol 1989, 81:181-185.

55. He XH, Xu LH, Liu Y, Zeng YY: Cloning of human beta-microglobulin gene and its high expression in Escherichia coli. Sheng Wu Gong Cheng Xue Bao 2004, 20:99-103.

56. Miyata $T$, Inagi $R$, Wada $Y$, Ueda $Y$, lida $Y$, Takahashi M, Taniguchi N, Maeda K: Glycation of human beta 2-microglobulin in patients with hemodialysis-associated amyloidosis: identification of the glycated sites. Biochemistry 1994, 33:12215-12221.

57. Sire J, Colle A, Pinatel MC, Fellous M, Manuel Y: beta2-Microglobulin in human seminal fluid (author's transl). Pathol Biol (Paris) 1978, 26:392-394.

58. Chard T, Parslow J, Rehmann T, Dawnay A: The concentrations of transferrin, beta 2-microglobulin, and albumin in seminal plasma in relation to sperm count. Fertil Steril 1991, 55:211-213.

59. Pacis RA, Pilat MJ, Pienta KJ, Wojno K, Raz A, Hogan V, Cooper CR: Decreased galectin-3 expression in prostate cancer. Prostate 2000, 4:118-123.

60. Brew K, Dinakarpandian D, Nagase H: Tissue inhibitors of metalloproteinases: evolution, structure and function. Biochem Biophys Acta 2000, 1477:267-283.

61. Bode W, Fernandez-Catalan C, Tschesche H, Grams F, Nagase H, Maskos K. Structural properties of matrix metalloproteinases. Cell Mol Life Sci 1999, 55:639-652.

62. Itoh $Y$, Binner $\mathrm{S}$, Nagase $\mathrm{H}$ : Steps involved in activation of the complex of pro-matrix metalloproteinase 2 (progelatinase A) and tissue inhibitor of metalloproteinases (TIMP)-2 by 4-aminophenylmercuric acetate. Biochem J 1995, 308:645-651.

63. Michaely $P$, Tomchick DR, Machius M, Anderson RG: Crystal structure of a 12 ANK repeat stack from human ankyrinR. EMBO J 2002, 21:6387-6396.

64. Bennett V, Baines AJ: Spectrin and ankyrin-based pathways: metazoan inventions for integrating cells into tissues. Physiol Rev 2001, 81:1353-1392. 
65. Neilsen PM, Cheney KM, Li CW, Chen JD, Cawrse JE, Schulz RB, Powell JA, Kumar R, Callen DF: Identification of ANKRD11 as a p53 coactivator. J Cell Sci 2008, 121:3541-3552.

66. Wong P, Borst DE, Farber D, Danciger JS, Tenniswood M, Chader GJ, Van Veen T: Increased TRPM-2/clusterin mRNA levels during the time of retinal degeneration in mouse models of retinitis pigmentosa. Biochem Cell Biol 1994, 72:439-446.

67. Leskov KS, Klokov DY, Li J, Kinsella TJ, Boothman DA: Synthesis and functional analyses of nuclear clusterin, a cell death protein. $J$ Biol Chem 2003, 278:11590-11600.

68. Jain D, Jain R, Eberhard D, Eglinger J, Bugliani M, Piemonti L, Marchetti P, Lammert E: Age- and diet-dependent requirement of DJ-1 for glucose homeostasis in mice with implications for human type 2 diabetes. J Mol Cell Biol 2012, 4:221-230.

69. Waanders LF, Chwalek K, Monetti M, Kumar C, Lammert E, Mann M: Quantitative proteomic analysis of single pancreatic islets. Proc Natl Acad Sci USA 2009, 106:18902-18907.

70. Okada M, Matsumoto K, Niki T, Taira T, Iguchi-Ariga SM, Ariga H: DJ-1, a target protein for an endocrine disrupter, participates in the fertilization in mice. Biol Pharm Bull 2002, 25:853-856.

doi:10.1186/1477-7827-11-38

Cite this article as: Sharma et al:: Functional proteomic analysis of seminal plasma proteins in men with various semen parameters. Reproductive Biology and Endocrinology 2013 11:38.

\section{Submit your next manuscript to BioMed Central and take full advantage of:}

- Convenient online submission

- Thorough peer review

- No space constraints or color figure charges

- Immediate publication on acceptance

- Inclusion in PubMed, CAS, Scopus and Google Scholar

- Research which is freely available for redistribution 